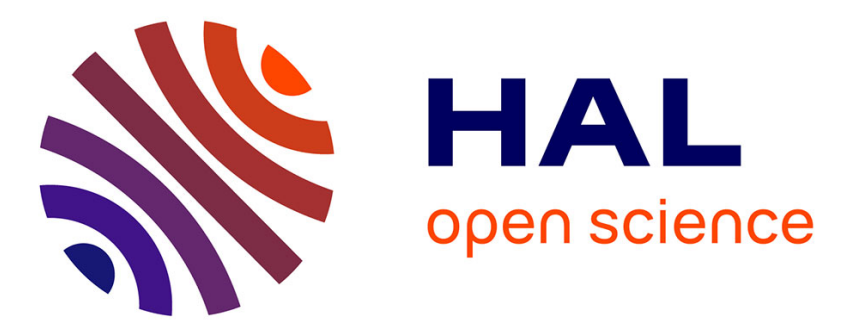

\title{
Using redox active molecules to build multilayered architecture on carbon fibers and the effect on adhesion in epoxy composites
}

\author{
Melissa K Stanfield, Daniel J Eyckens, Jérôme Médard, Philippe Decorse, \\ Jean Pinson, Luke Henderson.
}

\section{To cite this version:}

Melissa K Stanfield, Daniel J Eyckens, Jérôme Médard, Philippe Decorse, Jean Pinson, et al.. Using redox active molecules to build multilayered architecture on carbon fibers and the effect on adhesion in epoxy composites. Composites Science and Technology, 2020, pp.108564. 10.1016/j.compscitech.2020.108564 . hal-03047209

\section{HAL Id: hal-03047209 \\ https://hal.science/hal-03047209}

Submitted on 8 Dec 2020

HAL is a multi-disciplinary open access archive for the deposit and dissemination of scientific research documents, whether they are published or not. The documents may come from teaching and research institutions in France or abroad, or from public or private research centers.
L'archive ouverte pluridisciplinaire $\mathbf{H A L}$, est destinée au dépôt et à la diffusion de documents scientifiques de niveau recherche, publiés ou non, émanant des établissements d'enseignement et de recherche français ou étrangers, des laboratoires publics ou privés. 


\title{
Using redox active molecules to build multilayered architecture on carbon fibers and the effect on adhesion in epoxy composites
}

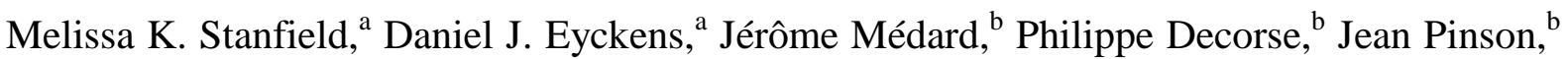 \\ and Luke C. Henderson. ${ }^{\text {a* }}$ \\ ${ }^{a}$ Institute for Frontier Materials, Deakin University, Geelong, Victoria 3220, Australia. \\ ${ }^{\mathrm{b}}$ Université de Paris, ITODYS, CNRS, F-75006 Paris, France.
}

Corresponding Author: luke.henderson@deakin.edu.au

\begin{abstract}
Carbon fibres with redox-active surface functionalities have shown potential applications in environmental remediation, and as burgeoning materials for structural batteries and super capacitors. In this work we describe the tethering of anthraquinone, capable of a reversible 2 electron transfer in aqueous medium, to the carbon fibre surface, and the corresponding effect on interfacial adhesion.
\end{abstract} The anthraquinone alone results in a $>150 \%$ improvement in interfacial shear strength and the redox activity is preserved. Further to this, we then use this conductive film as a means to grow an acrylic acid polymer on top of the anthraquinone base layer, characterised by water contact angle, infrared spectroscopy, and depth-profiling X-ray photoelectron spectroscopy. This outermost layer imparts additional benefit to fibre-to-matrix adhesion and preserves the redox activity of the modified carbon fibers. This work demonstrates the ability to grow dual component and covalently-attached sizings to the carbon fiber surface, without compromising the inherent benefits of the underlying carbon fibers.

Keywords: Aryldiazonium, Surface Modification, Composite, Anthraquinone, Carbon Fibers

\subsection{Introduction}

Carbon fibers are well known for their desirable properties, for example, high strength, light weight, corrosion resistance, conductivity, and negligible thermal expansion, and as such have been used in a myriad of applications.[1] In another guise, carbon fibers are also receiving a great deal of attention for their suitability as capacitors, structural batteries, and as a material to remove pollutants for environmental remediation.[1-3] As a form of carbon, these fibers have a relatively low surface area compared to porous carbon black, graphene, carbon nanotubes and carbon nanofibers, and these latter 
materials have been used extensively for energy storage applications.[2] Though this is counteracted to an extent by their ability to be easily woven and processed via well-established textile processes such as weaving and braiding into complex shapes. The manufacture of carbon fibers, the modification of their surface, and the corresponding effect on macroscopic properties, has been an area of intense investigation for decades.[3, 4] This has included the use of nanomaterial deposition, $[5]$ ceramic precursor materials, $[6]$ the use of various matrices, $[7,8]$ and the targeted application of composites to specific environments. $[9,10]$ Of the resins commonly used, and that which is used within this report, are thermoset polymers usually highly cross-linked and derived from epoxide containing monomers. Due to their common presence within composites, large research efforts have been put towards optimising their adhesion to various materials, including carbon fibers,[11] metals,[12, 13] and naturally occurring fibres to generate green composites.[14] Moreover, the use of other additives, such as nanomaterials (graphene, nanoparticles, etc.) these resins can be made to possess interesting functional properties.[15-17]

The choice to employ carbon fibers as the material of focus within this study was based on our historical experience. Also, the ability to fabricate carbon fibers with multi-functionality would have immediate impact on modern structures due to the widespread acceptance and use of carbon fiber reinforced composites. There have been numerous reports using the surface modification of carbon fibers with conducting polymers,[4-9] and electrolytes for use in structural batteries, though these are not typically accompanied by the evaluation of how these coatings influence fiber-to-matrix adhesion. This latter point is a critical aspect of all composites, and while it has been extensively researched for structural composites, the interfacial adhesion effected by conductive or redox active species on the fibre surface remains poorly understood. Recent work by Asp et al. showed that the interfacial adhesion for structural battery interfaces was reduced compared to commercial sizings in a vinyl ester resin, but was still viable for application in the field.[2] The area of structural batteries faces a myriad of challenges, which are being addressed, though balancing the trade-offs between efficiency, performance, and process-ability remain significant.

The ability of a material to undergo multiple electron processes in reduction-oxidation (redox) cycles has been used as a means to enhance the electrical performance of carbon materials for energy 
applications. Commonly multi-carbonyl compounds such as anthraquinone,[10-12] oxalate,[13] and organometallic species such as ferrocene $[14,15]$ are used to functionalise the carbon surface. Work from our group has focused intently on the use of aryldiazonium salts as a facile surface manipulation strategy, largely centred on carbon fibers.[16-21] The electrografting of these aryldiazonium salts occurs via the irreversible reductive cleavage of the Aryl- $\mathrm{N}_{2}{ }^{+}$bond to give the corresponding aryl radical and nitrogen gas. This highly reactive aryl radical is generated in close proximity to the carbon surface and thus is tethered to the surface via strong covalent C-C bonds.[22]

This study examines the use of anthraquinone (AQ) films as surface modifications for carbon fiber and determination of the corresponding effect on interfacial adhesion (Figure 1). Also examined within this study is the possibility to use the conductive AQ film as a means to initiate and grow a second polymeric layer on the first layer from the fiber surface. The desire to grow a second layer of polymer to the carbon fiber surface required a species within the initial layer able to reduce aryl diazonium salts to initiate radical polymerization. Thus, AQ served as an ideal candidate for the initial conducting layer as it possesses a reduction peak on carbon fiber (vide infra) at approximately $-1.0 \mathrm{~V}$ (vs. $\mathrm{Ag} / \mathrm{AgCl}$ in $\mathrm{ACN})$. Thus, it is able to easily reduce aryl diazonium salts, which typically possess a broad irreversible reduction peak centred at $-0.3 \mathrm{~V}(v s . \mathrm{Ag} / \mathrm{AgCl})$.[18] The ability to selectively install multiple surface chemistries as desired on the surface of carbon fibers will make significant gains towards the generation of gradient interface/interphases for optimal performance and the development of functional composites. 

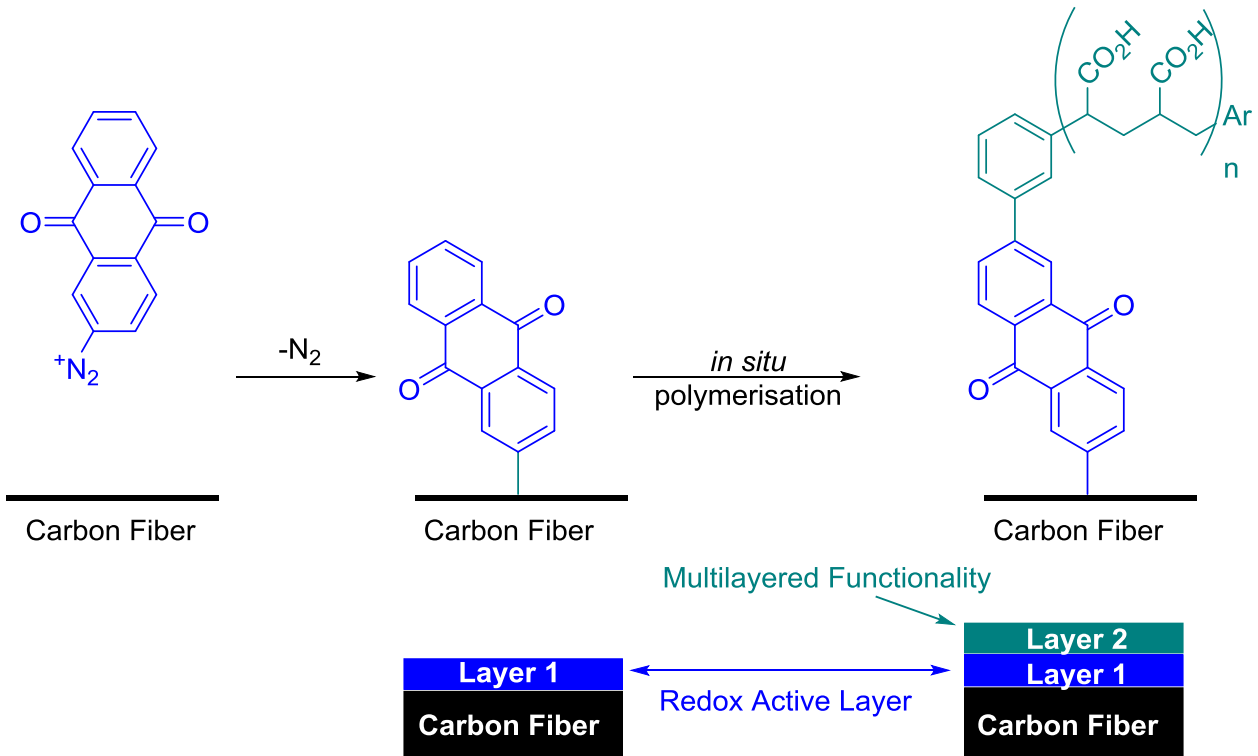

Figure 1 A schematic representation of the investigation undertaken within this work. The use of a redox active layer present on carbon fibers as a mediator to develop multilayered functionality in a composite.

\subsection{Experimental Design}

\subsection{Reagents}

See supporting information (SI) for carbon fiber and gold sputtered silica wafer preparation. The modified surfaces will be referred as Au- $A Q$ or CF- $A Q$ for a gold or carbon fiber surface modified by anthraquinone groups, respectively. Similarly, $\mathrm{Au}-A Q_{20}-\mathrm{COOH}$ for the bilayered film on gold and CF$A Q_{20}-\mathrm{COOH}$ for carbon fibers, with the subscript indicates the number of scans used for grafting, for example: $\mathrm{CF}-(A Q)_{5}$.

All chemicals were purchased from Sigma Aldrich (Australia) or Oakwood Chemical (USA), unless synthesised as outlined below.

\subsection{Synthesis of Aryl-diazonium tetrafluoroborate (Aryl- $\left.\mathbf{N}_{2}\right)$}

The diazonium salts were prepared from corresponding aniline according to procedures in the literature.[23] Nitrosonium tetrafluoroborate $(504 \mathrm{mg}, 4.34 \mathrm{mmoL})$ was added to $\mathrm{MeCN}$ in a 2-neck RBF under inert atmosphere and the solution was cooled to $-40{ }^{\circ} \mathrm{C}$. 4-Nitroaniline (500 $\mathrm{mg}, 3.62$ mmol) or 2-aminoanthraquinone $(500 \mathrm{mg}, 2.23 \mathrm{mmol}$ ) was added and stirred for 30 minutes. The mixture was warmed to room temperature over the following hour. Precipitation and collection of the 
desired products from diethyl ether $\left(0^{\circ} \mathrm{C}\right)$, gave the desired compound, determined to be analytically pure by ${ }^{1} \mathrm{H}$ NMR and ${ }^{19} \mathrm{~F}$ NMR.

\subsection{Electrochemical Grafting}

The electrochemical measurements and grafting procedures were carried out on an Autolab PGSTAT204. The working electrode was either a carbon fiber tow or gold coated silica wafer fixed in the cell using copper tape and an alligator clip. A leak-less silver/silver chloride reference electrode (ET069-1, eDaq) and a platinum mesh $\left(\right.$ area $\left.=2.5 \mathrm{~cm}^{2}\right)$ counter electrode were also used. Measurements were recorded through NOVA software. Electrochemical functionalisation was carried out as reported in the literature.[24] The grafting solution consisted of 2 millimolar $A Q-N_{2}$ in dry $\mathrm{MeCN}$ with 0.1 molar $\mathrm{TBAPF}_{6}$ as the supporting electrolyte. Once the electrografting was finished, the gold electrodes were washed and sonicated in ethanol for 60 seconds and dried under a stream of nitrogen. The modified carbon fibre tow was washed with acetone, dichloromethane, ethanol, and allowed to air dry.

\subsection{Fourier Transform Infrared Spectroscopy}

A Bruker LUMOS FTIR using ATR mode was used to obtained infrared measurements, using 256 scans and a scan resolution of $4 \mathrm{~cm}^{-1}$. To process the data, Bruker OPUS 7.0 software was used.

\subsection{Atomic Force Microscopy (AFM)}

AFM data was obtained using a Bruker Multimode 8 AFM instrument with a Bruker FMV-A tip model (tip radius $8 \mathrm{~nm}$, spring constant nominally $2.8 \mathrm{~N} / \mathrm{m}$ ). Contact tapping mode was used to perform the experiments. NanoScope Analysis (Bruker, version 1.5) was used to process the acquired data.

\subsection{Ellipsometry}

The film thickness of each sample was calculated using a M-2000XI Spectroscopic Ellipsometer (J.A. Woollam Co., Inc., Lincoln, NE, USA). Three measurements were taken from each sample at angles of incidence of $60^{\circ}, 65^{\circ}, 70^{\circ}$ and $75^{\circ}$ at wavelengths of 210-1685 nm. Film thicknesses were calculated by fitting a B-Spline model on top of a silicon substrate with native oxide layer using CompleteEASE software version 4.92 (J.A. Woollam Co., Inc., USA). 


\subsection{X-ray Photoelectron Spectroscopy (XPS)}

XPS measurements were performed using a K-Alpha ${ }^{+}$spectrometer (Thermo Fisher Scientific, EastGrinstead, UK) fitted with a microfocused and monochromatic Al Ka X-ray source (1486.6 eV, spot size: $400 \mu \mathrm{m}, 12 \mathrm{kV}, 6 \mathrm{~mA}$ as emission intensity). The pass energy was set to 150 and $40 \mathrm{eV}$ for the survey and the high-resolution spectra, respectively. The spectra were calibrated against the $\mathrm{C}-\mathrm{C} / \mathrm{C}-\mathrm{H} \mathrm{C} 1 \mathrm{~s}$ component set at $285 \mathrm{eV}$. The chemical composition was determined with version 5.9902 Avantage software by using the manufacturer sensitivity factors. The K-Alpha ${ }^{+}$system is equipped with an Argon MAGCIS (Mono-Atomic and Gaz Cluster Ion Source, $\mathrm{Ar}^{+}$and $\mathrm{Ar}_{\mathrm{n}}{ }^{+}$) dual ion source. To performed profile analysis, we have used accelerated $\mathrm{Ar}_{2000}{ }^{+}$gas cluster ion beam at an energy of $4000 \mathrm{eV}$, for specified ionic bombardment durations and with an ion beam size leading to a crater close to $4 \mathrm{~mm}^{2}$. The ion gun was placed at an incidence angle of $30^{\circ}$ with respect to the surface of the samples, with no rotation. During ion beam bombardment, the X-ray source was blanked.

\subsection{Water Contact Angle (WCA)}

Water contact angles of modified gold wafers used a custom-built angle goniometer and a water droplet volume of $\sim 3 \mu \mathrm{L}$. The measurements were collected over a 10 -second time span at a 0.66 second intervals. Determination of WCA was carried out automatically, using software (SFECam2008, KSV Instruments Ltd., Helsinki, Finland). Multiple measurements (minimum of 3) were taken from each sample, the mean angle was obtained from the data set and used as the final value for the measurement.

\subsection{Determination of interfacial shear strength (IFSS)}

To determine the mechanical properties of the composite with modified fiber, interfacial shear strength was employed. The methods used are consistent with our and other's previously published work (refer to SI).[25]

\subsection{Statistical Analysis}


A Student's T-test was undertaken to determine statistically significant changes in data. This assumed equal variance and a P-value of less than 0.05 was considered statistically significant. To denote statistical significance throughout the manuscript we have used asterisks $(*)$.

\subsection{Results and Discussion}

\subsection{Electrografting of AQ on gold and carbon fibers.}

Grafting of gold surfaces with the diazonium salt of 2-aminoanthraquinone $\left(A Q-N_{2}\right)$

Initially, preliminary experiments were carried out on flat gold wafers, as this is a common practice for surface modifications and allows for easy comparison to the literature. While a gold surface may be considered a poor representation of the carbon fiber surface, it is worth noting that our previous work in the covalent sizing of carbon fibers used a similar adaptation of electrochemical procedure from gold to carbon with great success.[16] In particular, the use of a flat, gold surface allows the collection of better IRRAS spectra, and grants a greater ability to measure film thickness than carbon fiber surfaces.

The electrochemical grafting of the diazonium salts of 1- and 2-aminoanthraquinone (as the corresponding tetrafluoroborate salt) has been investigated, in MeCN.[12, 24, 26-29] The reduction of the diazonium salt on a gold electrode is observed at $0.18 \mathrm{~V} / \mathrm{SCE}$ that disappears on the second scan; it is followed by the first reversible wave of anthraquinone at $\mathrm{E}^{\circ}=-0.93 \mathrm{~V} / \mathrm{SCE}$ corresponding to the formation of the radical anion (Figure 2, AQ"). This wave is followed by a second at more negative potential $\mathrm{E}^{\circ}=-1.59 \mathrm{~V} / \mathrm{SCE}$ corresponding to the formation of the dianion (Figure 2, $\mathrm{AQ}^{2-}$ ).[12]

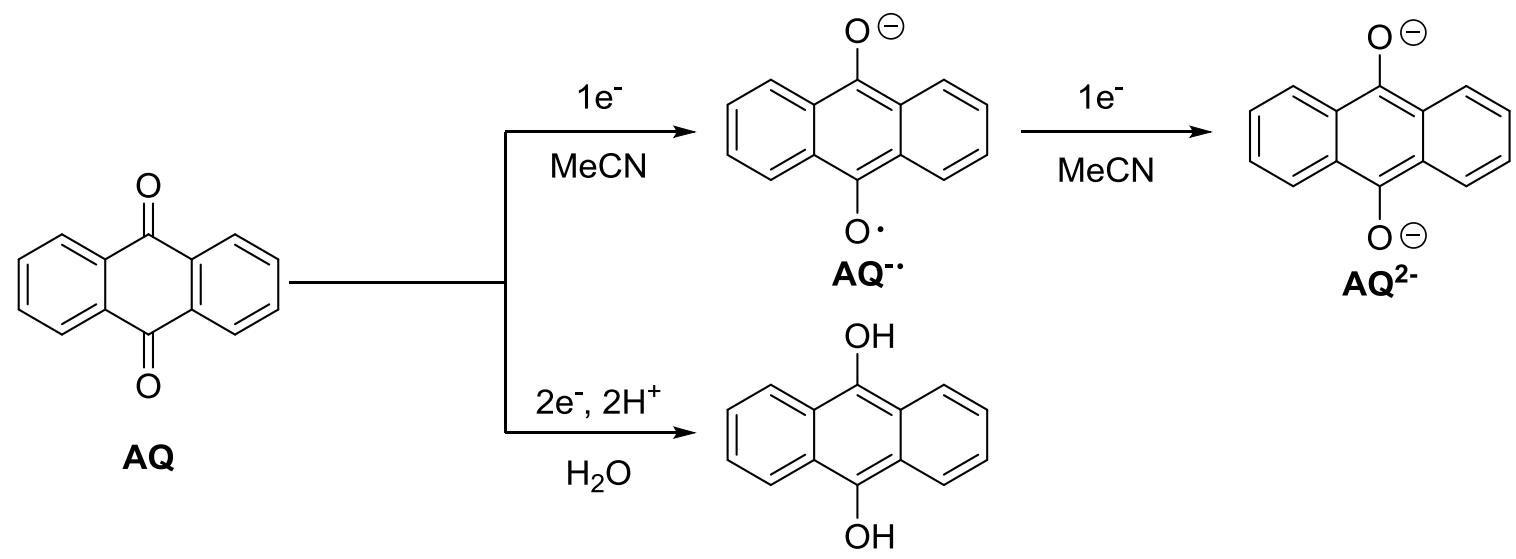

$\mathrm{AQH}_{2}$

Figure 2 The reduction of anthraquinone in aprotic and protic medium. 
In this medium, with anthraquinonediazonium and 4-nitrobenzenediazonium, a very interesting phenomenon was reported by Daasjberg et al. $[12,24,28]$ upon repetitively scanning the diazonium reduction wave and the first wave of anthraquinone. The latter increases upon repetitive scanning, indicating the repeated grafting of anthraquinone groups, generating a covalently bound film composed of many AQ units. This corresponds to thicker films up to $50 \mathrm{~nm}$. This reduction of the anthraquinone moiety to its radical anion permits the transfer of electrons to the surface of the film, and therefore, the reduction of more diazonium salts, resulting in the growth of the film. This is a very interesting method for obtaining thick films with a redox behaviour.

In our work, the diazonium salt of 2-aminoanthraquinone (AQ- $\left.N_{2}\right)$ was grafted to a gold electrode in to $0.1 \mathrm{M} \mathrm{TBAPF}_{6}$ in $\mathrm{MeCN}$ solution (scanning between 0.1 and -1.5 $\mathrm{V} /(\mathrm{Ag} / \mathrm{AgCl}))$, obtaining sample $\mathrm{Au}-A Q_{20}$. After grafting of the gold electrode, rinsing and transfer to a fresh electrolytic solution $\left(0.1 \mathrm{M} \mathrm{TBAPF}_{6}\right.$ in $\left.\mathrm{MeCN}\right)$ the reversible voltammogam of $\mathrm{Au}-A Q$, is observed at $\mathrm{E}^{\circ}=-0.89 \mathrm{~V} /(\mathrm{Ag} / \mathrm{AgCl}$ ) (Figure 3) in good agreement with the redox potential of $\mathrm{AQ}$ itself in $\mathrm{MeCN}$ : $\mathrm{E}^{\circ}=-0.93 \mathrm{~V} / \mathrm{SCE}$.[30] Once films were grafted to the gold surface, we measured the thickness of the film obtained by repeated reduction of $A Q-N_{2}$, in $\mathrm{MeCN}$ (scanning between 0.1 and $-1.5 \mathrm{~V} /(\mathrm{Ag} / \mathrm{AgCl})$ ). The film thickness was measured to be $14 \pm 1.03 \mathrm{~nm}$, and it is worth noting that in our previous experience in the translation of surface modification from gold plates to carbon fibers, film thicknesses measured on gold are magnified on carbon fibers. This was described in our previous work, where the thickness of an electrochemical initiation of a covalent polymer was measured at $\sim 150 \mathrm{~nm}$ on a metallic surface, but was increased to at $\sim 250-350 \mathrm{~nm}$ on carbon fibers.[16, 31] This is attributed to the gold surface being effectively 2-dimensional when compared with the typical curved and striated surface of carbon fibers, though faster electron transport may also be responsible. 


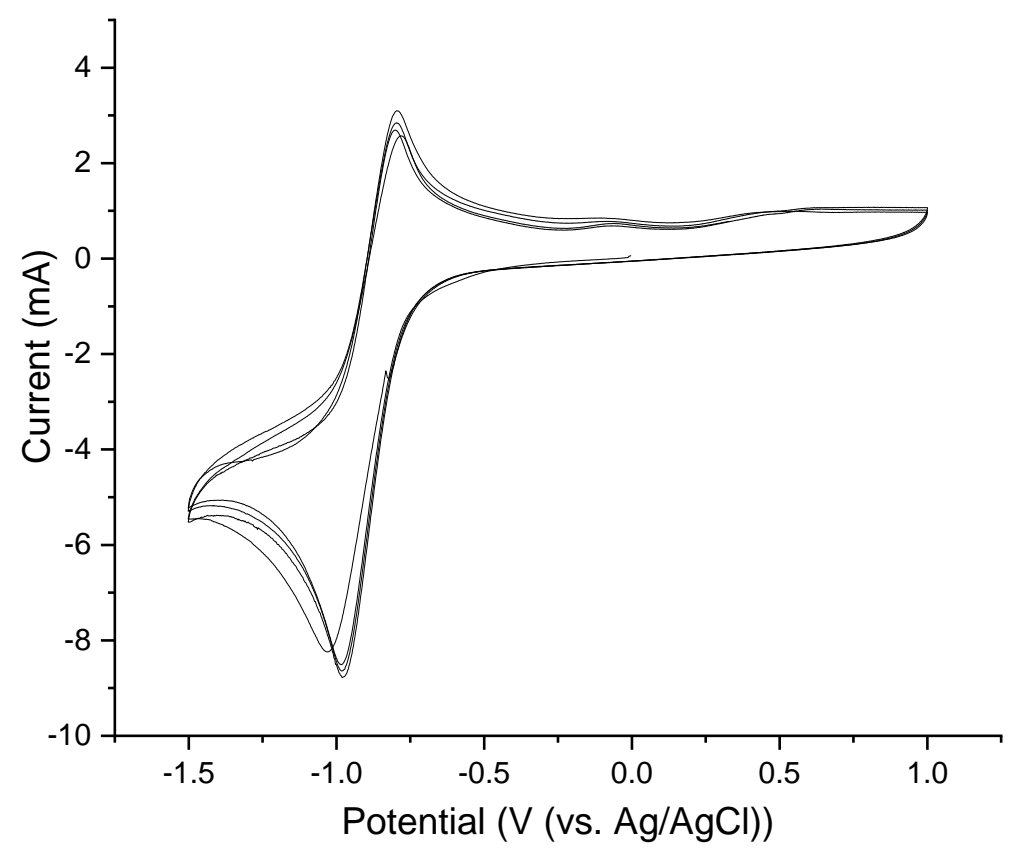

Figure 3 Reversible redox peak of the grafted anthraquinone moiety on a gold wafer (Au- $\left.A Q_{20}\right)$.

\subsection{Grafting of Carbon Fibers with $\mathrm{AQ}-\mathrm{N}_{2}$}

The films of anthraquinone were achieved using 5 and 20 cycles ( $\operatorname{scan}$ rate $=1.0 \mathrm{Vs}^{-1}$, from 0.1 to -1.5 $\mathrm{V} /(\mathrm{Ag} / \mathrm{AgCl})$, behind the peak of anthraquinone), in $0.1 \mathrm{M} \mathrm{TBAPF}_{6} / \mathrm{MeCN}\left(\mathrm{CF}-A Q_{5}\right)$. These modified carbon fibers were carefully rinsed and transferred to an anhydrous solution of $0.1 \mathrm{M}$ $\mathrm{TBAPF}_{6} / \mathrm{MeCN}$. The reversible voltammogram of $\mathrm{CF}-A Q_{5}$ (Figure 4) presents a partly reversible voltammogram, compared to that of the AQ on a gold surface. This disparity in reversibility is likely due to the inherent presence of $-\mathrm{COOH}$ groups on the surface of the carbon fiber, installed during manufacture, that protonate the radical anion. Despite only partial reversibility, the presence of these peaks affirms for the successful grafting of anthraquinone moieties to the fiber surface. In search of thicker films, the number of scans was increased to 20 sweeps $\left(\mathrm{CF}-A Q_{20}\right)$. The FT-IR spectrum (Figure SI3) of CF- $A Q_{20}$ shows strong peaks appearing at $1726 \mathrm{~cm}^{-1}$, significantly higher than 2aminoanthraquinone itself, which presents carbonyl bands at $1689 \mathrm{~cm}^{-1}$. It is possible that this peak is a combination of the carbonyl of the grafted AQ species and the carbonyl of the native carboxylic acids present on the fibers, as has been reported previously.[18] Notably, the absence of signal in the $3000-3500 \mathrm{~cm}^{-1}$ region indicates that there are no $\mathrm{OH}$ groups and that the film is entirely formed of 
anthraquinone groups, as hydroquinone presents a strong band at $3262 \mathrm{~cm}^{-1}$ due to the presence of phenolic moieties.

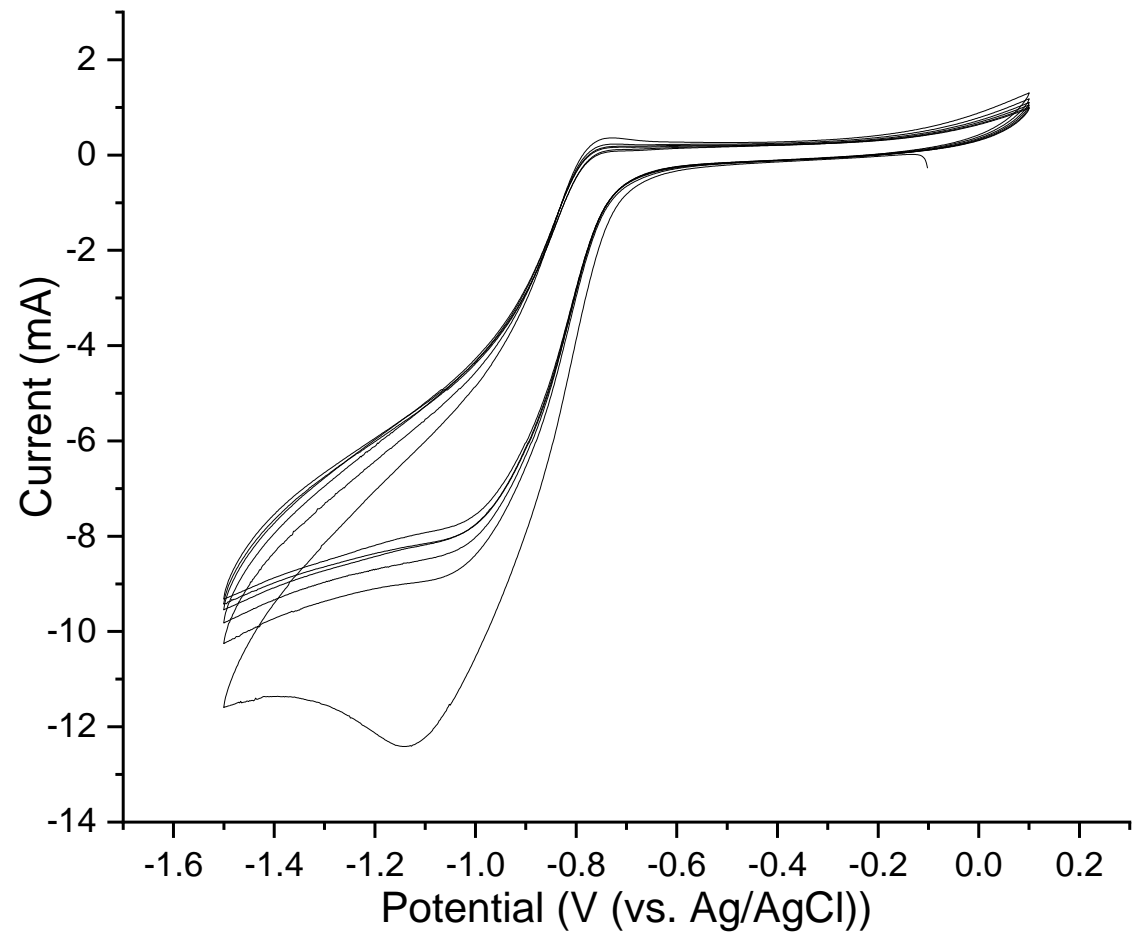

Figure 4 Cyclic voltammetry of $\mathrm{CF}_{-} \mathrm{AQ}_{5}$ transferred to $0.1 \mathrm{M} \mathrm{TBAPF}_{6}$ in $\mathrm{MeCN}$ solution (vs. $\mathrm{Ag} / \mathrm{AgCl})$, scan rate $=1.0 \mathrm{Vs}^{-1}$.

Taken together, these data support the successful grafting of AQ to the fiber surface under two different conditions (CF- $A Q_{5}$ and CF- $\left.A Q_{20}\right)$. Unfortunately, the innate curvature and striated surface of the fibers (functionalized or otherwise) prevents the determination of film thickness using such techniques as ellipsometry for comparison with the cyclic voltammograms. With these in hand, our focus turned to assessing the physical characteristics of the fibers to ensure that their fundamental and desirable properties had not decreased as a result of surface modification. The pristine fibers (unsized and not surface treated) were found to have a tensile strength $3.71 \pm 0.07 \mathrm{GPa}$, and a Young's modulus of $262.6 \pm 0.73 \mathrm{GPa}$. Functionalization to give the $\mathrm{CF}-A Q_{5}$ fibers returned a tensile strength of

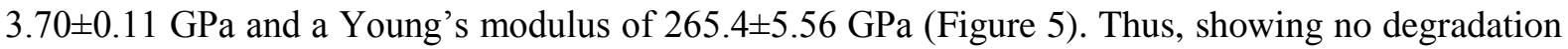
of the fiber properties as a result of this surface treatment, only the introduction of redox properties. 
Interestingly, the tensile strength of the CF- $A Q_{20}$ fibers was statistically indistinguishable $(3.75 \pm 0.06$ GPa) to control fibers, though surface modification had occurred at the expense of stiffness, as this had been reduced to $251.0 \pm 3.37 \mathrm{GPa}$. Despite this slight reduction $(\sim 5 \%)$ in fiber stiffness, these fibers are still suitable as polymer reinforcement and thus suggests that as the functionalization process had minimal impact on fiber properties.

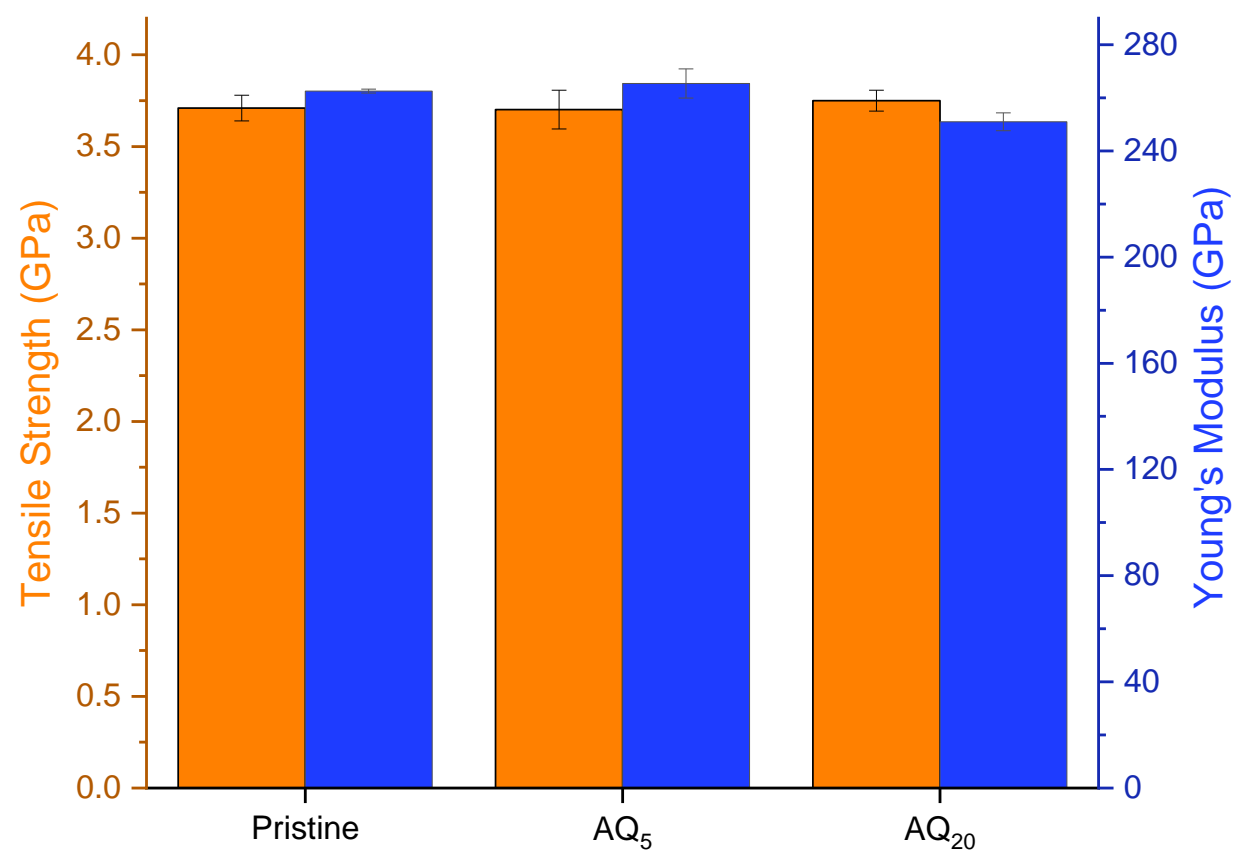

Figure 5 Tensile strength and Young's modulus of pristine, $\mathrm{CF}-\mathrm{AQ}_{5}$ and $\mathrm{CF}-\mathrm{AQ}_{20}$ surface modified carbon fibers. Error bars show standard deviation, error bars for pristine sample (Young's Modulus) is too small to be seen, $*$ denotes statistical significance $(\mathrm{P}<0.05)$.

Finally, the determination of interfacial shear strength of the functionalized fibers was undertaken using the single filament fragmentation test (SFFT) in an epoxy resin, as per our previous publications.[32-34] The pristine fiber samples showed a very poor IFSS (18.1 $\pm 0.7 \mathrm{MPa})$, as would be expected, as this sample had not undergone any surface treatment or sizing.

When evaluating IFSS for the CF- $A Q_{5}$ and CF- $A Q_{20}$ functionalized fibers, significant increases in IFSS of $64 \%(29.6 \pm 1.8 \mathrm{MPa})$ and $151 \%(45.4 \pm 6.8 \mathrm{MPa})$, respectively, were observed (Figure 6). The increased IFSS for CF- $A Q_{20}$ was attributed to the thicker film of small molecules grafted to the fiber surface enhancing the degree with which these grafted species penetrated into the interphase. Previously, we have shown that a large degree of the IFSS increases observed are the result of the energy expended by the lateral drag of the surface tethered molecules through the 
composite interphase.[35, 36] This effect is quite sensitive to thickness and degree of penetration, consistent with the thicker films resulting in greater enhancement of this effect. In this instance, this would be complemented by the surface grafted molecules possessing both fully conjugated aromatic structure and the presence of the carbonyl (ketone) units would potentially interact with the epoxy by hydrogen bonding.

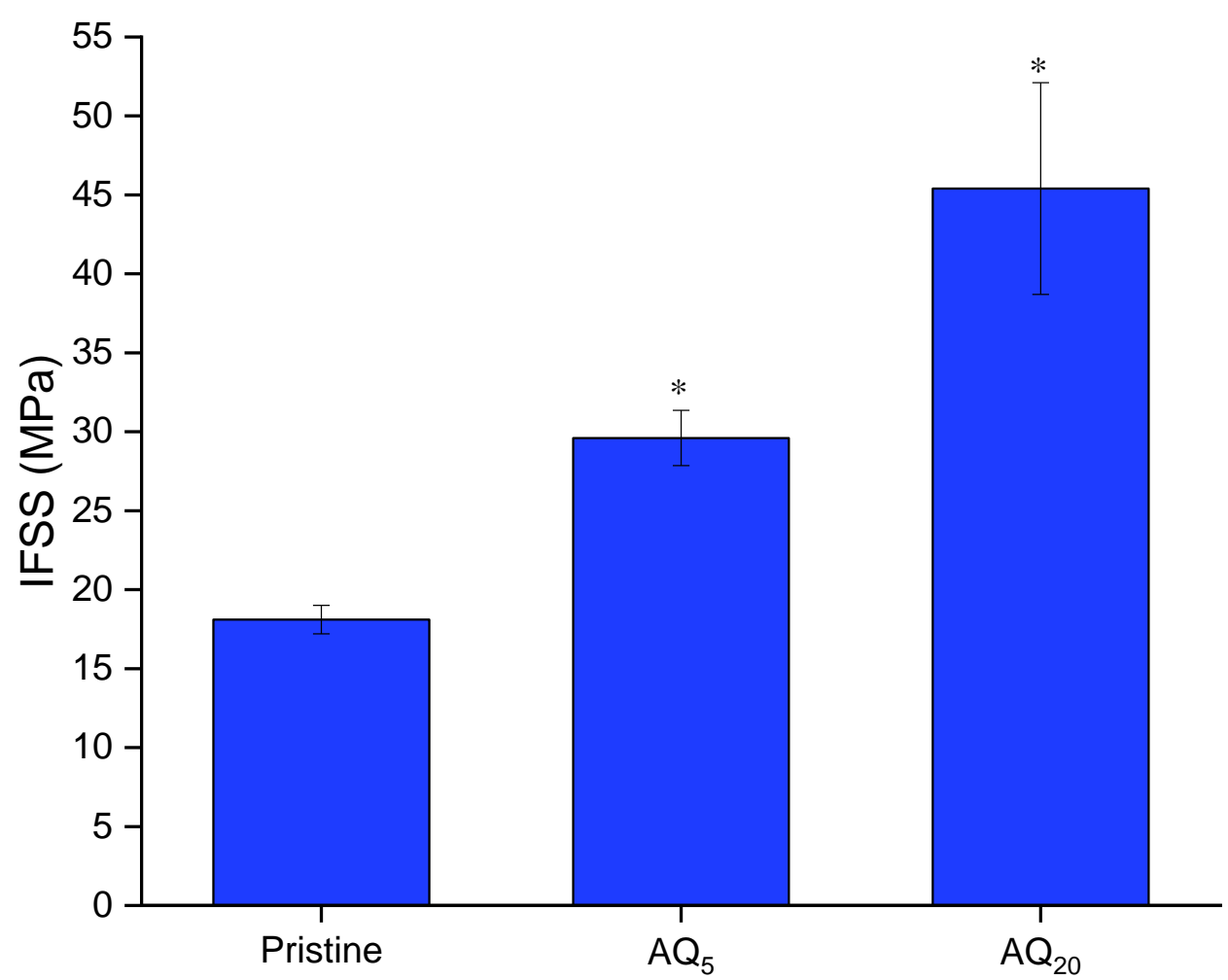

Figure 6 The interfacial shear strength of CF- $A Q_{5}$ and CF- $A Q_{20}$ surface modified carbon fibers. Error bars show standard error, ${ }^{*}$ denotes statistical significance $(\mathrm{P}<0.05)$.

With this encouraging data in hand, our attention turned to the sequential modification of the carbon fiber surface to generate multi-layered surfaces which could potentially imbue the carbon fibers with unique functionality while not compromising on adhesion. While these anthraquinone units do not, in this instance, compromise on adhesion, their physical penetration into the epoxy interphase may compromise their electrochemical activity. Thus, our interest was to grow an additional layer of polymer on top of the anthraquinone layer to introduce a spacing unit between the resin and the fiber surface.

3.3 Electro grafting of a bilayer AQ /acrylic acid on gold and carbon fibers 
Recently, following the work of Deniau,[37] we described the surface modification of carbon fibers that had been subjected to an in situ polymerization process in aqueous acidic solution. In that instance, the growth of poly(acrylic acid) had been effected on the surface of the carbon fibers, leading to IFSS being improved by significantly (i.e. > 200\%).[16] Therefore, we hypothesized that these AQ modified fibers could be utilized in initiating this same polymerization, then this would result in a layered interface (Figure 7), significantly increasing IFSS. Additionally, this concept would serve as a platform upon which solid or polymeric electrolytes could be covalently linked to carbon surfaces for enhanced performance in structural batteries and capacitors.

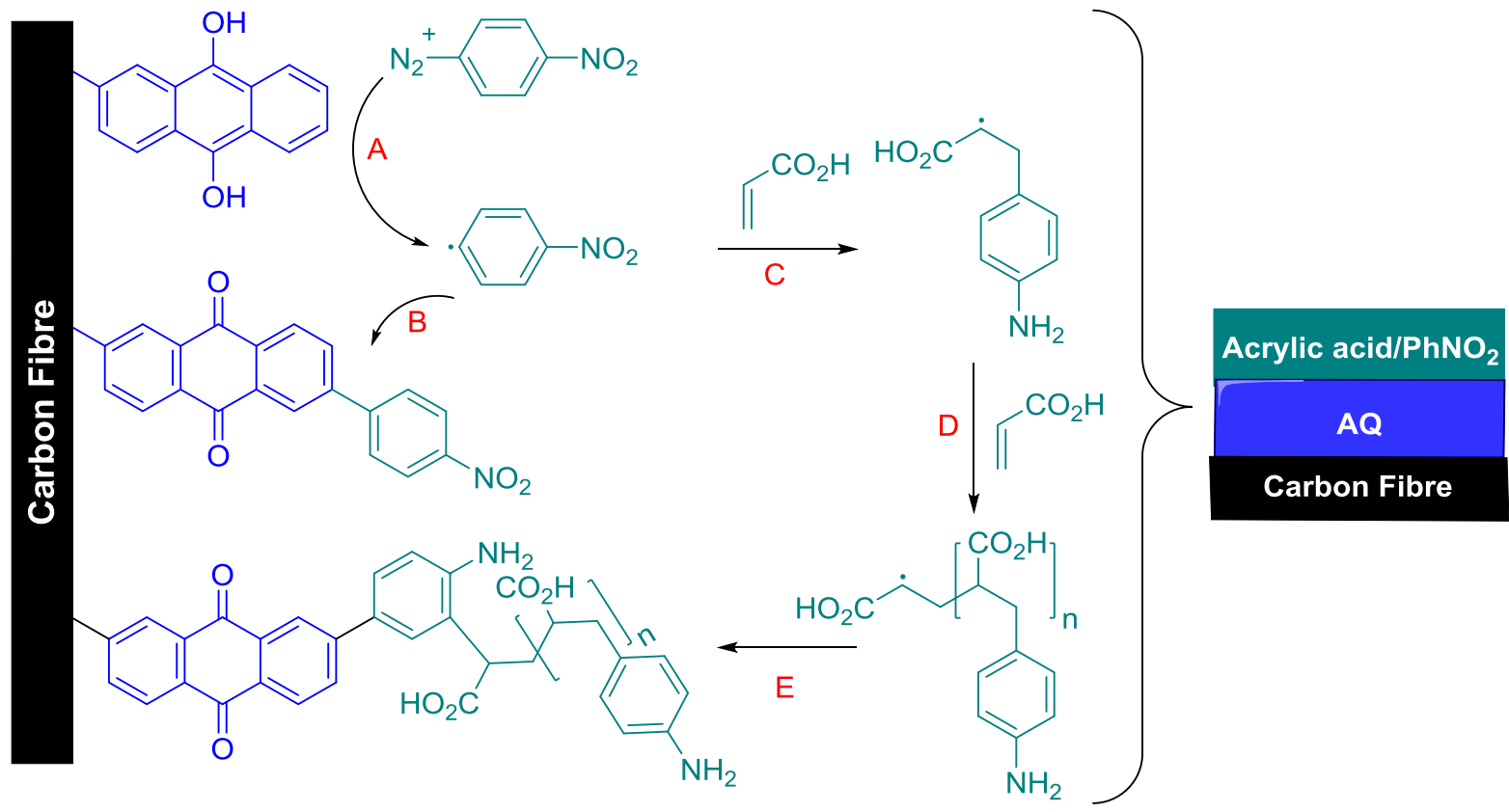

Figure 7 Using the AQ layer as a means to initiate the reduction of a second aryldiazonium salt in the presence of acrylic acid to generate a layered interface. This process occurs by using the redox activity of AQ to reduce the incoming 4-nitrophenyldiazonium salt (Step A), which can both attach to the already installed AQ layer (Step B), or diffuse into the solution to initiate the polymerization of acrylic acid (Step $\mathbf{C}$ and $\mathbf{D}$ ), which then diffuses to the surface of the fiber to covalently bind to the modified surface (Step E). Note that during this process a portion of the nitrophenyl groups are concomitantly reduced to the corresponding $\mathrm{NH}_{2}$ group (in the presence of $\mathrm{COOH}$ groups of acrylic acid). The exact point of this occurring is unknown and thus the above schematic is illustrative only.

Diazonium salts are stable in an acidic medium, but the reduction of anthraquinone takes place through a reversible $2 \mathrm{e}^{-}+2 \mathrm{H}^{+}$as presented in Figure 2. In aqueous solution, on an edge plane pyrolytic graphite (EPPG) electrode, the $\mathrm{E}^{\circ}$ of $\mathrm{AQ}-\mathrm{SO}_{3} \mathrm{H}$ shifts with $\mathrm{pH} .[38-40]$ When 2aminoanthraquinonesulfonate is grafted to an EPPG electrode, the reversible system shifts from 
approximately $-0.2 \mathrm{~V} / \mathrm{SCE}$ at $\mathrm{pH} 0$ to $-0.9 \mathrm{~V} /(\mathrm{Ag} / \mathrm{AgCl})$ at $\mathrm{pH} 14 .[39,40]$ For Glassy Carbon (GC) modified electrodes with 1- or 2-aminoanthraquinone groups, a similar behaviour is observed and a reversible wave is observed at $\mathrm{E}^{\circ} \sim-0.15 \mathrm{~V} / \mathrm{SCE}$ in acidic medium .[41] In $0.05 \mathrm{M} \mathrm{H}_{2} \mathrm{SO}_{4}$, the reduction wave of the diazonium salt $\left(A Q-N_{2}\right)$ has been observed at $0.24 \mathrm{~V} /(\mathrm{Ag} / \mathrm{AgCl})$.

An electrode was modified in an aqueous acidic $\left(0.01 \mathrm{M} \mathrm{H}_{2} \mathrm{SO}_{4}\right)$ solution of $A Q-N_{2}(2 \mathrm{mM})$. After grafting the electrode was rinsed and transferred to $0.1 \mathrm{M} \mathrm{TBAPF}_{6}$ in $\mathrm{MeCN}$ solution to check the redox activity of the aqueous grafted $\mathrm{AQ}$, the reversible voltammogam of $\mathrm{Au}-A Q$, is observed at $\mathrm{E}^{\circ}=$ $-0.82 \mathrm{~V} /(\mathrm{Ag} / \mathrm{AgCl})$ consistent with earlier observations within this work and as reported for AQ in $\operatorname{MeCN}\left(E^{\circ}=-0.93 \mathrm{~V} / \mathrm{SCE}\right.$; Figure SI2).[30] This shows that when grafted in $0.01 \mathrm{M} \mathrm{H}_{2} \mathrm{SO}_{4}$ the AQ moiety retains its redox behaviour, therefore facilitating the first step (Figure 7, Step A) of the proposed polymerization mechanism; the reduced form $\mathrm{AQH}_{2}$ being able to reduce the diazonium salt $A Q-N_{2} \cdot[30]$

Therefore, grafting with 4-nitrophenyldiazonium tetrafluoroborate $(2 \mathrm{mM})$ and acrylic acid $(0.7 \mathrm{M})(-$ 1.5 $\mathrm{V}$ vs. $\mathrm{Ag} / \mathrm{AgCl})$ was conducted, as per our previously reported procedures.[42] A cyclic voltammogram shows the reversible system of AQ followed by the reduction of the nitrophenyl group and the reduction of $\mathrm{H}^{+}$to $\mathrm{H}^{*}$ at more negative potentials (Figure SI4).

The reaction was also performed on $1 \times 1 \mathrm{~cm}$ gold surface to obtain surface data such as FT-IR, film thickness, and water contact angle, which as mentioned previously are challenging on carbon fiber surfaces. An Au-AQ $Q_{20}$ plate was modified under the above conditions. Note that at this final potential $(-1.5 \mathrm{~V} /(\mathrm{Ag} / \mathrm{AgCl}))$ in acidic aqueous medium both $\mathrm{AQ}$ and 4-nitrophenyl groups are reduced to $\mathrm{AQH}_{2}$ and 4-aminophenyl groups (Figure 7). Analysis of this double layered electrode $\mathrm{Au}-A Q_{20}-A A$ revealed that the top film (polyacrylic acid) was $8 \pm 3.4 \mathrm{~nm}$, and the bottom film $14 \pm 1.0 \mathrm{~nm}$, giving a total film thickness of approximately $22 \mathrm{~nm}$. Analysis by FTIR (Figure 8 ) showed the presence of carbonyl peaks at $1677 \mathrm{~cm}^{-1}$ that includes both the $\mathrm{C}=\mathrm{O}$ signal of acrylic acid $\left(1705 \mathrm{~cm}^{-1}\right)$ and anthraquinone $\left(1680 \mathrm{~cm}^{-1}\right)$. 


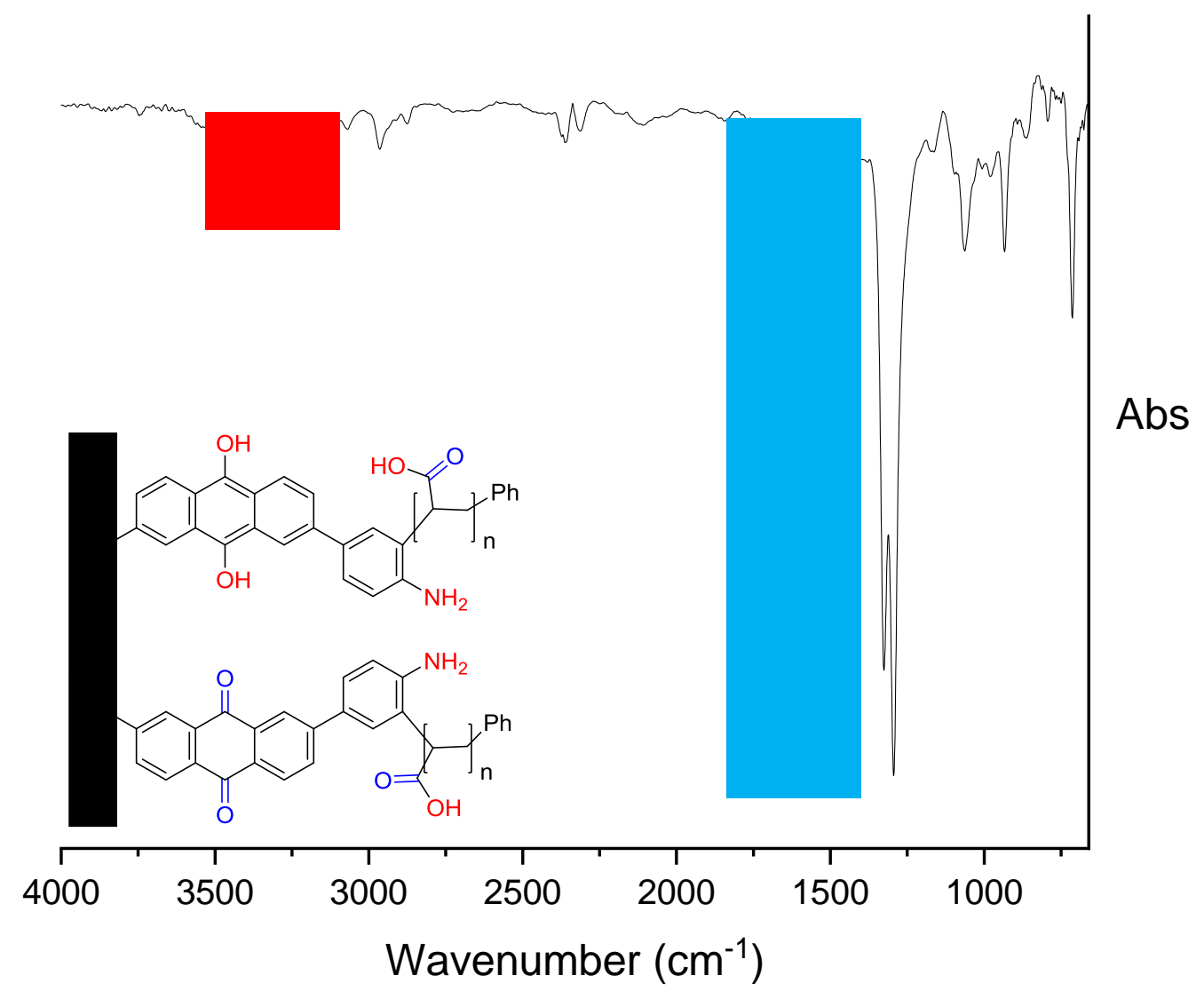

Figure 8 FT-IR analysis of the double layered electrode $\left(\mathrm{Au}-A Q_{20}-A A\right)$, the strong presence of a two carbonyl peaks carbonyl peak at $1677 \mathrm{~cm}^{-1}$ corresponding to both acrylic acid and AQ. The $1323 \mathrm{~cm}^{-1}$ and $1293 \mathrm{~cm}^{-1}$ band correspond to $\mathrm{C}-\mathrm{N}$ group and the $-\mathrm{NO}_{2}$ signals are not observed.

The band at $1593 \mathrm{~cm}^{-1}$ is assigned to the vibration of the aromatic band of anthraquinone, as the anthraquinone itself appears at $1592 \mathrm{~cm}^{-1}$.[44] The $-\mathrm{NO}_{2}$ signals are not observed due to their reduction, but $\mathrm{COOH}$ (from acrylic acid), $\mathrm{OH}$ (from $\mathrm{AQH}_{2}$ ) and $\mathrm{NH}_{2}$ (from the reduction of nitrophenyl groups) bands are observed in the $3000-4000 \mathrm{~cm}^{-1}$ range. To corroborate that the surface modification process had been successful, atomic force microscopy (AFM) was conducted on this multi-layered surface. The formation of a film is clearly observed in the AFM images of the modified gold surface (Figure 9). The main characteristic of this image is the uniform aspect of the film and the absence of obvious pinholes at this scale $(1 \mu \mathrm{m}$ scale with a grainy surface and an RMS roughness of $2.2 \mathrm{~nm}$ ), though of course this does not preclude their presence on a smaller scale (vide infra).

\footnotetext{
** https://sdbs.db.aist.go.jp/sdbs
} 


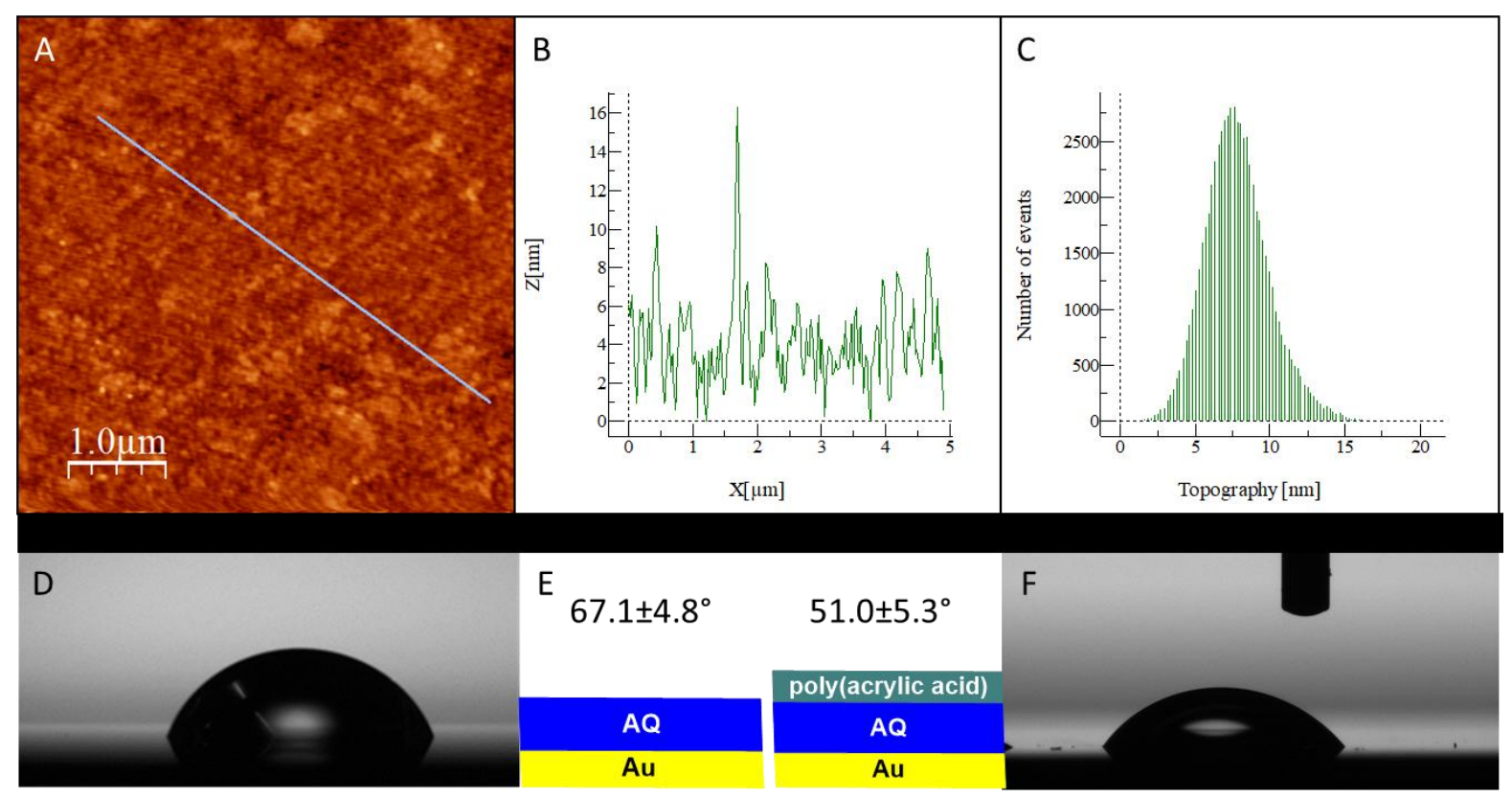

Figure 9 A) AFM sampled area; B) Height variations along AFM tip course; C) Distribution of events versus topography; D) Water droplet on Au- $A Q_{20}$ surface; E) Schematic of the surfaces being examined by water contact angle, and the corresponding angles; F) Water droplet on Au- $A Q_{20}-A A$.

Using water contact angle (WCA) as an alternative means to determine the nature of the outermost layer was useful as the AQ and poly(acrylic acid) layers should possess vastly different surface polarities. Indeed, the Au- $A Q_{20}$ functionalized electrode gave a WCA of $67.1 \pm 4.8^{\circ}$, while after the growth of the second acrylic acid polymer layer this was significantly decreased to $51.0 \pm 5.3^{\circ}$, as would be expected, due to the increased polarity of poly(acrylic acid).

Finally, to ensure that the installation of a second polymer layer on top of the AQ priming layer, does not hinder its redox behavior, the cyclic voltammetry was examined. The $A u-A Q_{5}-A A$ electrodes were then transferred to an $\mathrm{MeCN}$ with $0.1 \mathrm{M} \mathrm{TBAPF}_{6}$ solution and analyzed using cyclic voltammetry. This revealed (Figure 10) that the underlying AQ moieties still present a redox behavior $\mathrm{E}^{\circ}=-0.95 \mathrm{~V}$ (vs. $\mathrm{Ag} / \mathrm{AgCl}$ ), despite the presence of a bonded poly(acrylic acid) phase that could provide protons, note however that the electron transfer is slower $\Delta \mathrm{Ep}=0.25 \mathrm{mV}$ by comparison to Figure $3 \Delta \mathrm{Ep}=$ $0.18 \mathrm{mV}$. A slight shift to more negative potentials was observed relative to our previous examination (Figure 3). This is not unexpected given that the chemical environment of the electrode surface has 
been significantly changed and the structure of the AQ is likely to have been altered during the grafting of the 4-nitrophenyldiazonium reduction (Figure 7).

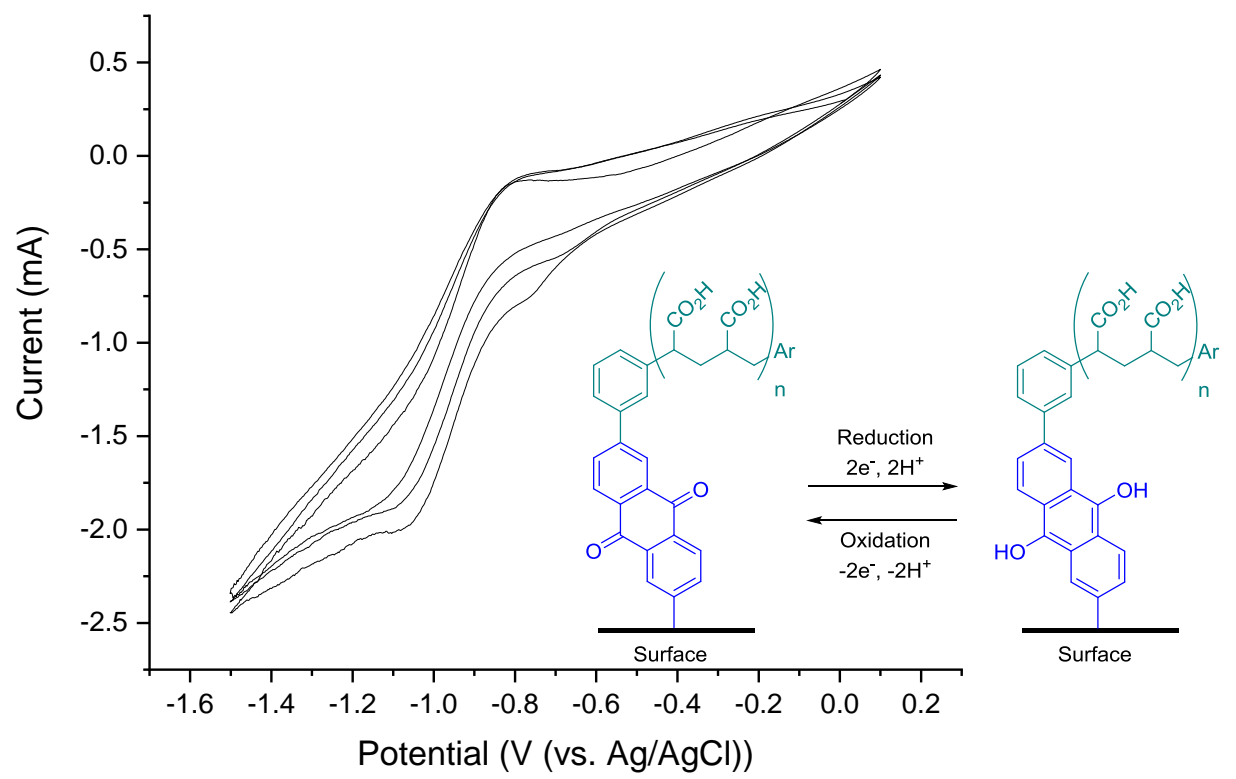

Figure 10 Cyclic voltammogram showing the retention of redox activity for the AQ groups tethered to the fiber surface after a poly(acrylic acid) layer has been grafted on top. Cyclic voltammogram of Au- $A Q_{20}-A A$ in $0.1 \mathrm{M} \mathrm{TBAPF}_{6}$ in $\mathrm{MeCN}$ ( $v s . \mathrm{Ag} / \mathrm{AgCl}$ ), Scan rate $=1.0 \mathrm{~V} \mathrm{~s}^{-1}$, reversible wave is observed at $\mathrm{E}^{\circ} \sim-0.95 \mathrm{~V}$ (vs. $\left.\mathrm{Ag} / \mathrm{AgCl}\right)$.

These analyses combined support the formation of a dual layered surface on the gold electrode, though to further confirm that this double layer of polymers was present, we undertook an XPS depth profiling experiments with $\mathrm{Au}-A Q_{5}-A A$ (Figure 11). This technique uses charged $\mathrm{Ar}_{\mathrm{n}}{ }^{+}$argon clusters (2000 ions for $4 \mathrm{keV}$ ) to gently ablate the surface bound polymer giving the chemical signature of the film in the z-axis. Though, to get a baseline of the presented surface chemistry, analysis by XPS (without milling) of the double-layered surface was recorded. The survey spectrum indicates the presence of Au4f (4.5\%), C1s (76.5\%), N1s (2.4\%), and O1s (16.6\%). In spite of the $18 \mathrm{~nm}$ thick organic film Au4f is still visible which may indicate the presence of pinholes.

The $\mathrm{C} 1 \mathrm{~s}$ region can be deconvoluted into several contributions, these are signals at $284.8 \mathrm{eV}(60.9 \%)$, $287.1 \mathrm{eV}(12.5 \%)$, and $289.2 \mathrm{eV}(3.1 \%)$. These signals to the $\mathrm{C} 1 \mathrm{~s}$ contribution can be attributed to the polymer backbone $(\mathrm{C}-\mathrm{C})$ bonds, the $\underline{\mathrm{C}}=\mathrm{O}$ ketone of the AQ moiety, and the $\underline{\mathrm{C}}=\mathrm{O}(\mathrm{OH})$ of the carboxylic acid, respectively. In the N1s spectrum, the only discernible peak is located at $400 \mathrm{eV}$ and not the expected $406 \mathrm{eV}$, typical of highly oxidized $\mathrm{NO}_{2}$ groups. The absence of this peak is due to the 
in situ reduction of the $\mathrm{NO}_{2}$ group during grafting and under the XPS beam. Indeed, under identical XPS conditions the reduction of $\mathrm{NO}_{2}$ to $\mathrm{NH}_{2}$ is possible, in this instance it seems that the abundance of acidic protons from the poly(acrylic acid) layer favoured this reduction to all observed nitrogen in the film. With this baseline spectrum in hand, the depth-profile of the dual layered film was examined. The surface of the gold electrodes was etched for intervals of 30 seconds with $\mathrm{Ar}_{n}{ }^{+}$argon clusters and an XPS spectrum was recorded at each interval. Assuming that gold electrode possesses two layers of polymer, it would be expected that the $\mathrm{C} 1 \mathrm{~s}(289 \mathrm{eV}, \mathrm{COOH})$ peak would be detected in a high concentration initially. Though, as erosion of the top layer occurs, the relative amount of $\mathrm{C}=\mathrm{O}$ contribution from the carboxylic acid should decrease relative to the other constituents, such as the $\mathrm{C}=\mathrm{O}$ contribution from the $\mathrm{AQ}$ and the $\mathrm{Au} 4 \mathrm{f}$ surface.

Analysis of the XPS profile data shows that is indeed what is observed (Figure 11), the signal attributable to acrylic acid decreases while the $\mathrm{C}=\mathrm{O}$ signal of $\mathrm{AQ}$ remains constant (i.e. relative ratio increases). Also as would be expected, the Au4f signal also increases with increasing etch time. This data, in addition to the WCA and FT-IR data described above, is consistent with the installation of a dual layer polymer on the surface of the gold electrode.

With confidence in the ability to install a secondary layer on top of the initial AQ film, we focused on applying this methodology to carbon fibers. In doing this we noted that (after installation of the second layer) the fibers became rigid, similar to commercially available fibers which possess a heavy thermoplastic sizing, an effect we have observed previously, when covalently grafting the fibers with only poly(acrylic acid).[16] 


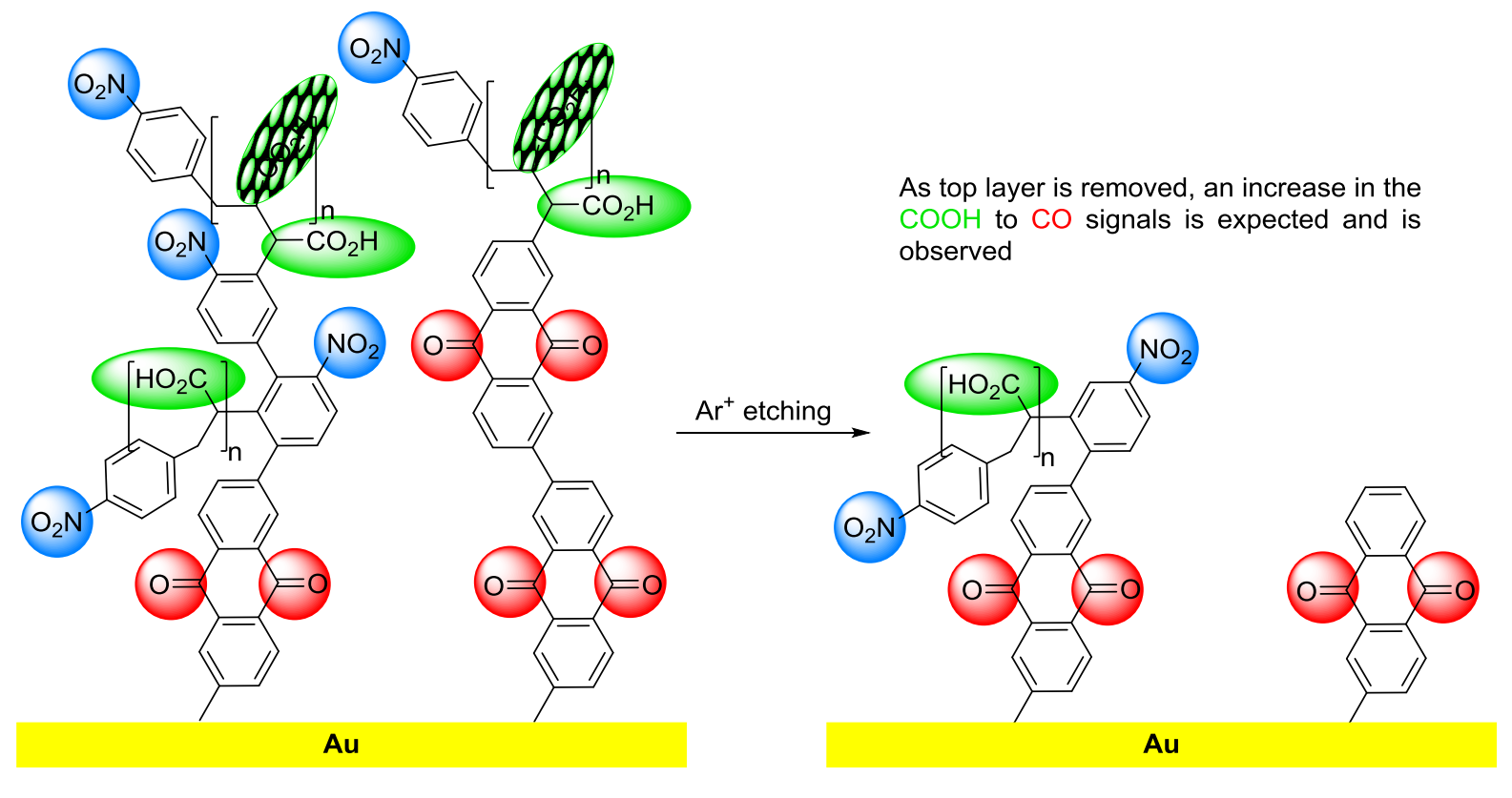

$t=0 s$

$t=190 s$

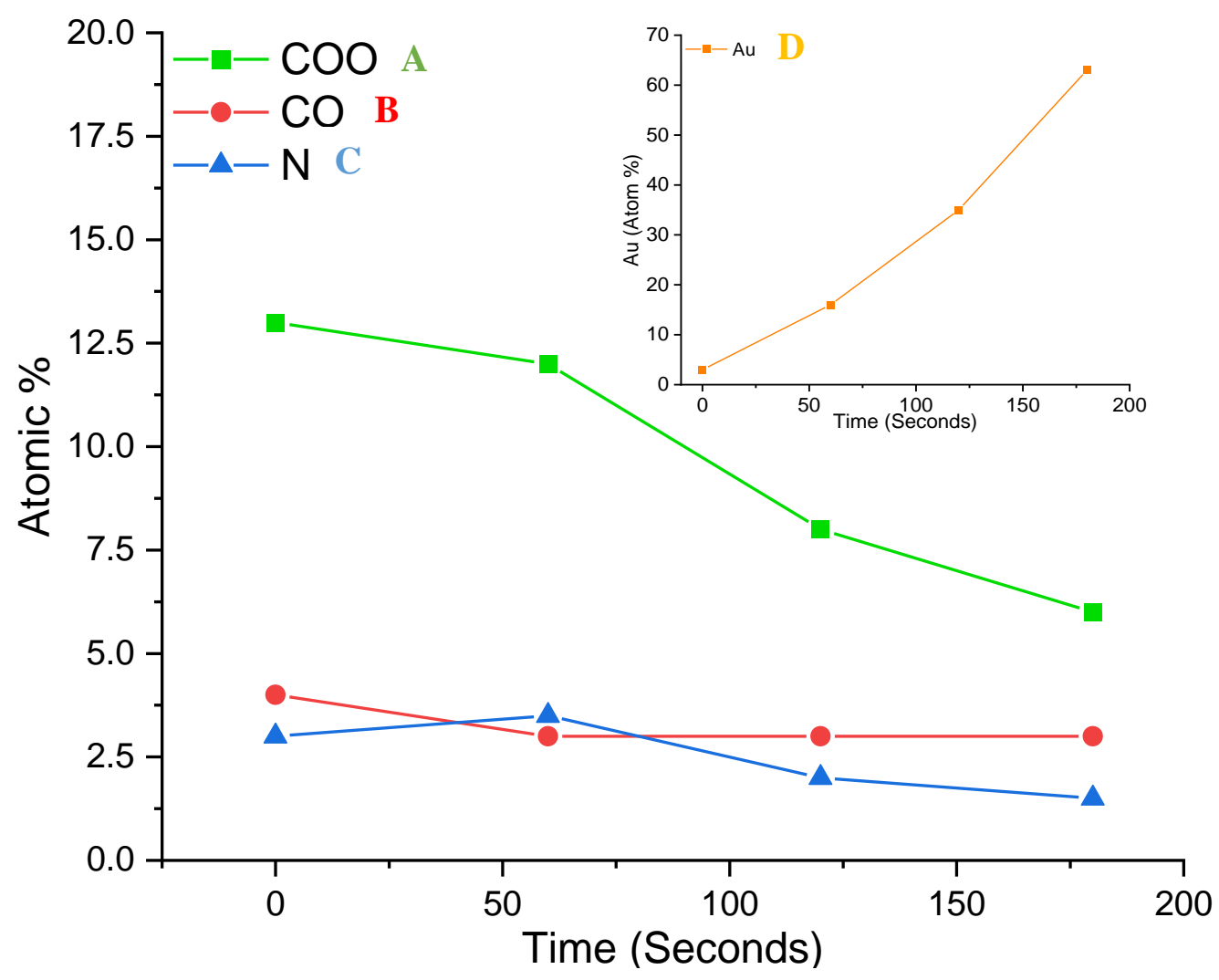

Figure 11 Top: generic representation of the gold electrode surface after installation of the dual polymer layer before ablation ( $\mathrm{t}=0$ seconds) and after ablation $(\mathrm{t}=180$ seconds); Bottom: Intensities of the $\mathrm{C} 1 \mathrm{~s}$ contributions at a) $289.2 \mathrm{eV}(-\mathrm{COOH})$ and b) $287.0 \mathrm{eV}(\mathrm{C}=\mathrm{O}, \mathbf{c}), \mathrm{N} 1 \mathrm{~s}$ and d) Au4f over etching time, indicating the passage through the poly(acrylic acid) layer towards the AQ and aryl nitro species present from initial diazonium salt reduction. 
These fibers with dual layer functionality exhibit an increased tensile strength $(4.18 \pm 0.09 \mathrm{GPa})$ relative to the pristine fibers $(3.71 \pm 0.07 \mathrm{GPa})$, a $15 \%$ increase, and retained a similar Young's modulus (256.05 $\pm 2.43 \mathrm{GPa}$ ) (Figure 12). This significant increase in tensile strength, we propose, is due to the growth of the polymer from the surface of the carbon fibers. Unlike a sizing or coating applied to the fiber surface, the approach used in this work uses the innate conductivity of the carbon fibers to initiate the polymerization process. As such, polymerization can initiate from within defects within the fiber structure, this serves to reinforce these defects, therefore providing less stress concentrations for fiber failure to initiate when under tension.

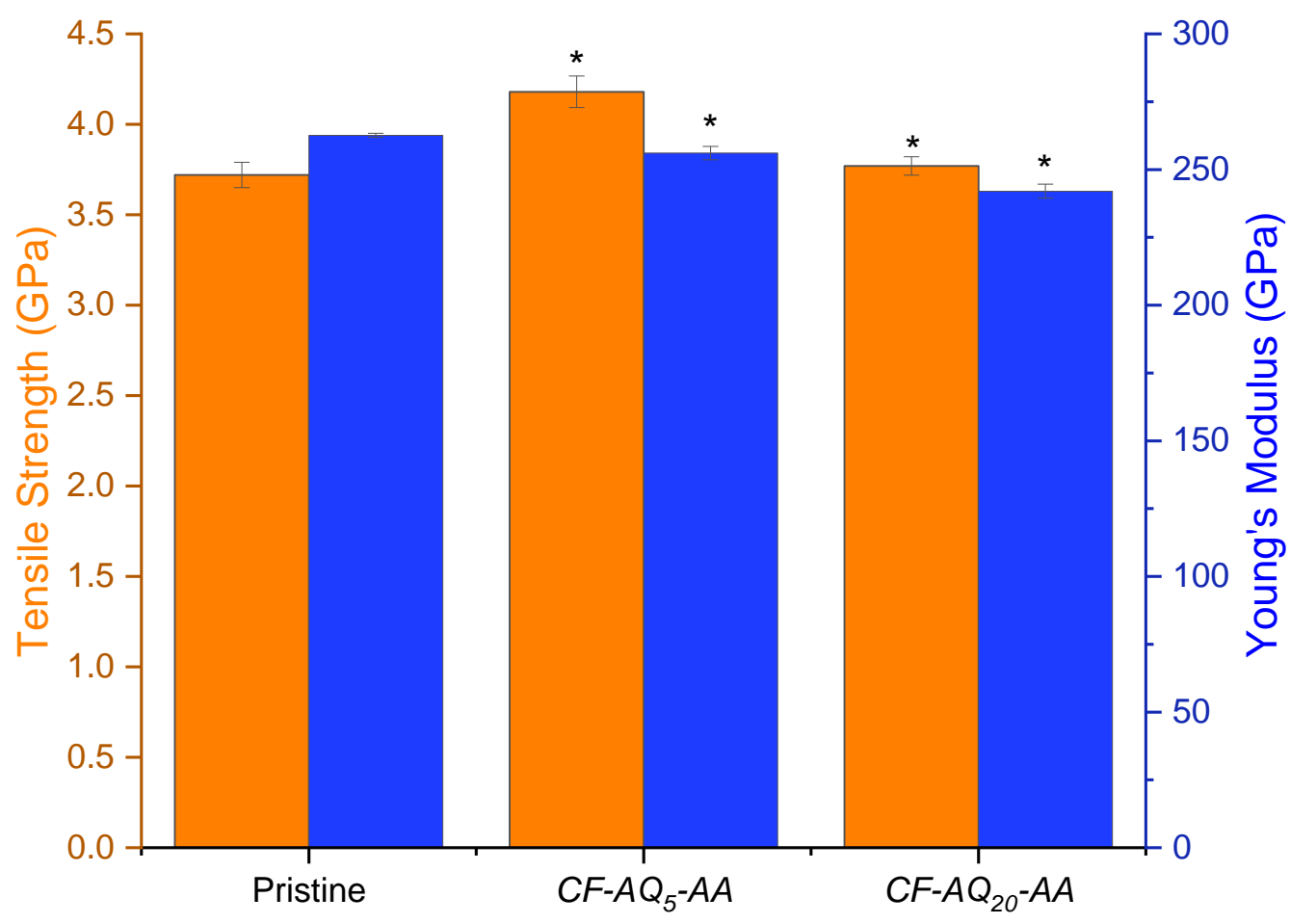

Figure 12 Tensile strength and Young's modulus for Pristine and CF- $A Q_{5}-A A$ and CF- $A Q_{20}-A A$. Error bars show standard deviation, $*$ denotes statistical significance $(\mathrm{P}<0.05)$.

Interestingly, when evaluating the IFSS of these fibers (Figure 13), the CF- $A Q_{5}-A A$ sample showed an additional $90 \%$ improvement relative to the parent $A Q_{5}$ fibers, a cumulative improvement of $153 \%$, relative to pristine fibers $\left(45.7 \pm 9.4 \mathrm{MPa} v s .18 .1 \pm 0.7 \mathrm{MPa}\right.$, respectively). Surprisingly, the CF- $A Q_{20^{-}}$ $A A$, possessed a similar IFSS compared to just the $A Q_{20}$ functionalized sample, prior to polyacrylic acid growth. While this is counter-intuitive, we attributed this result to the thicker AQ films slowing down the electron transfer to the nitrophenyl diazonium salt, thus limiting the extent to which 
poly(acrylic acid) is growth from the surface. This outcome is advantageous for the processing of carbon fiber via this methodology in a continuous line, as the initial installation of the AQ conductive layer using only 5 sweeps can be carried out very rapidly.

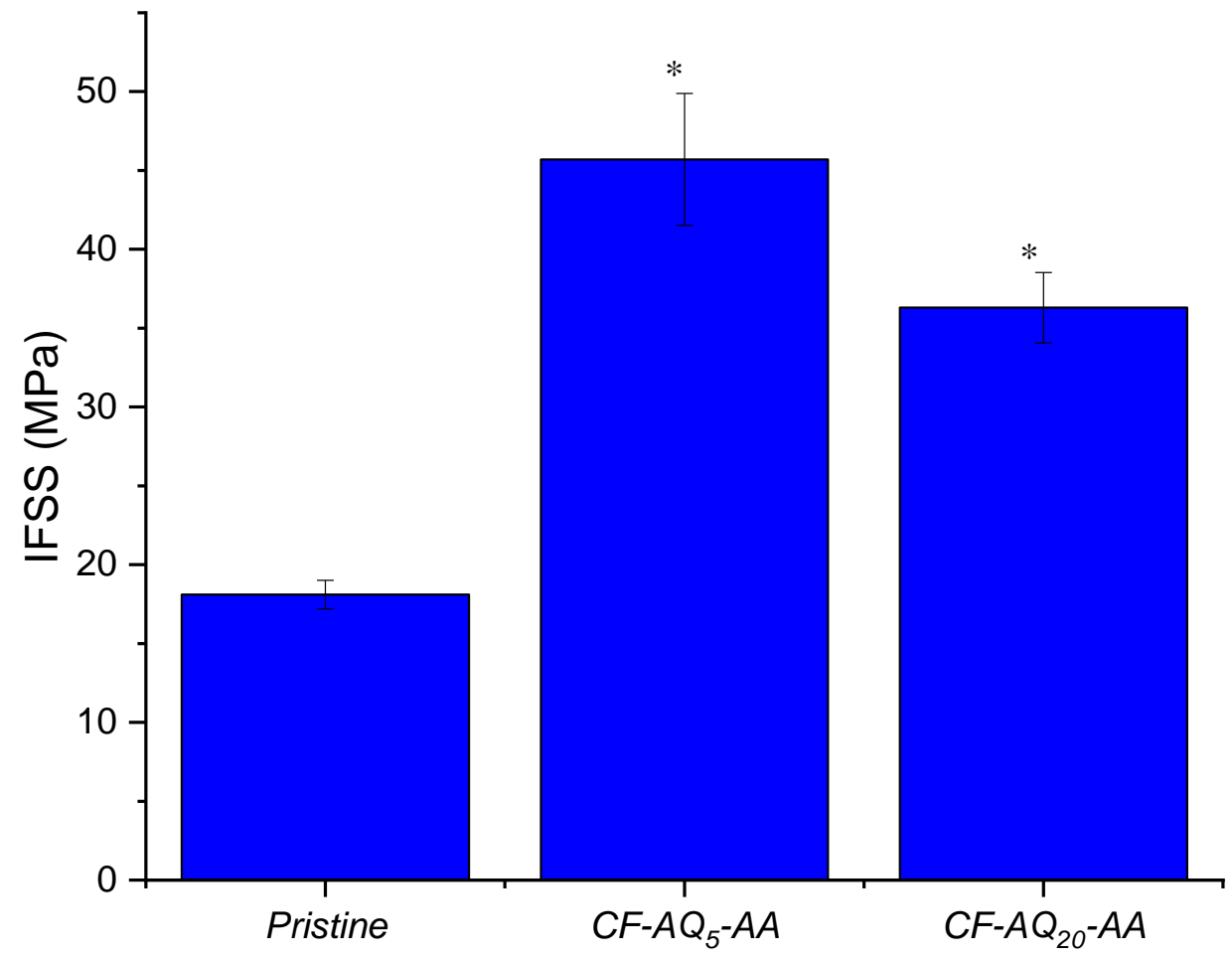

Figure 13 IFSS for CF- $A Q_{5}-A A$ and CF- $A Q_{20}-A A$ grown on the surface. Error bars show standard error, ${ }^{*}$ denotes statistical significance $(\mathrm{P}<0.05)$.

A similar grafting procedure was attempted on pristine carbon fibers, taking the potential back to -2.1 $\mathrm{V}$ (vs. $\mathrm{Ag} / \mathrm{AgCl}$ ) for both 5 and 20 cycles. This potential is much more negative than the onset of reduction of $\mathrm{H}^{+}$in acidic aqueous solution for the $A Q_{5}$ and $A Q_{20}$ samples and was investigated for the potential to improve electron transfer through the grafted AQ films. These samples were then subjected to the same polymerization conditions (again using $-2.1 \mathrm{~V}$ (vs. $\mathrm{Ag} / \mathrm{AgCl}$ )) to graft the polyacrylic acid to both, unfortunately no noteworthy results were observed compared to this work at lower reductive potentials. While disappointing, this outcome defines a working potential that would be suitable for these materials as applied to structural energy storage applications.

\subsection{Conclusions}

In conclusion, we have surface modified carbon fibers, in acidic aqueous solution, with anthraquinone films, able to undergo multiple redox processes. Carbon fibers with reversible oxidation-reduction 
properties are of value to areas such as environmental remediation, energy storage and structural batteries.[41] We show that the grafting of these AQ units using varying the number of potential sweeps can lead to significant gains in IFSS. Further we demonstrate the ability to use this conductive film as an anchor for the covalent attachment of a secondary polymer, in this case polyacrylic acid, to the carbon fibers. This was initially shown on a gold electrode, and characterized using FT-IR, water contact angle, and depth-profiling XPS. Adaptation of this process to the AQ functionalized fibers conferred an additional 90\% improvement in IFSS to fibers bearing just the surface grafted AQ. Attempts at using a more aggressive surface modification protocol, in the form of more extreme reductive potentials, highlighted a deleterious effect on IFSS, attributed to the degradation of the surface bound moieties.

\section{Acknowledgements}

The authors gratefully acknowledge Deakin University, this research was conducted with support from the Australian Government via the Australian Research Council World Class Future Fiber Industry Transformation Research Hub (IH140100018), ARC Training Centre for Lightweight Automotive Structures (IC160100032) and Discovery projects (DP180100094)). This work was also partially supported by the Office of Naval Research (N62909-18-1-2024) and was performed in part at the Deakin and Swinburne University node of the Australian National Fabrication Facility. A company established under the National Collaborative Research Infrastructure Strategy to provide nano- and microfabrication facilities for Australian researchers. ANR (Agence Nationale de la Recherche) and CGI (Commissariat à l'Investissement d'Avenir) are gratefully acknowledged for their financial support of this work through Labex SEAM (Science and Engineering for Advanced Materials and devices), ANR-10-LABX-096 and ANR-18-IDEX-00.

\section{References}

[1] L.E. Asp, E.S. Greenhalgh, Structural power composites, Compos. Sci. Technol. 101 (2014) 41.

[2] J. Xu, W. Johannisson, M. Johansen, F. Liu, D. Zenkert, G. Lindbergh, L.E. Asp, Characterization of the adhesive properties between structural battery electrolytes and carbon fibers, Compos. Sci. Technol. 188 (2020) 107962. 
[3] S. Leijonmarck, T. Carlson, G. Lindbergh, L.E. Asp, H. Maples, A. Bismarck, Solid polymer electrolyte-coated carbon fibres for structural and novel micro batteries, Compos. Sci. Technol. 89 (2013) 149-157.

[4] M. Liu, S. He, W. Fan, Y.-E. Miao, T. Liu, Filter paper-derived carbon fiber/polyaniline composite paper for high energy storage applications, Compos. Sci. Technol. 101 (2014) 152-158.

[5] Q. Pei, X. Bi, Electrochemical preparation of electrically conducting polyurethane/polyaniline composite, J. Appl. Polym. Sci. 38(10) (1989) 1819-1828.

[6] F. Ke, J. Tang, S. Guang, H. Xu, Controlling the morphology and property of carbon fiber/polyaniline composites for supercapacitor electrode materials by surface functionalization, RSC Adv. 6(18) (2016) 14712-14719.

[7] J.O. Iroh, R. Rajagopalan, Electrochemical synthesis of polyaniline-polypyrrole composite coatings on carbon fibres in aqueous toluene sulphonate solution, Surf. Eng. 16(6) (2000) 481-486.

[8] H.-T. Chiu, J.-S. Lin, Electrochemical deposition of polypyrrole on carbon fibres for improved adhesion to the epoxy resin matrix, J. Mater. Sci. 27(2) (1992) 319-327.

[9] J.O. Iroh, G.A. Wood, Physical and chemical properties of polypyrrole-carbon fiber interphases formed by aqueous electrosynthesis, J. Appl. Polym. Sci. 62(10) (1996) 1761-1769.

[10] G. Pognon, T. Brousse, L. Demarconnay, D. Bélanger, Performance and stability of electrochemical capacitor based on anthraquinone modified activated carbon, J. Power Sources 196(8) (2011) 4117-4122.

[11] H.J. Amezquita-Garcia, E. Razo-Flores, F.J. Cervantes, J.R. Rangel-Mendez, Anchorage of anthraquinone molecules onto activated carbon fibers to enhance the reduction of 4-nitrophenol, J. Chem. Technol. Biotechnol. 90(9) (2015) 1685-1691.

[12] A. Bousquet, M. Ceccato, M. Hinge, S.U. Pedersen, K. Daasbjerg, Redox Grafting of Diazotated Anthraquinone as a Means of Forming Thick Conducting Organic Films, Langmuir 28(2) (2012) 1267-1275.

[13] H.J. Amezquita-Garcia, J.R. Rangel-Mendez, F.J. Cervantes, E. Razo-Flores, Activated carbon fibers with redox-active functionalities improves the continuous anaerobic biotransformation of 4nitrophenol, Chem. Eng. J. 286 (2016) 208-215.

[14] L. Gan, J. Song, S. Guo, D. Jańczewski, C.A. Nijhuis, Side chain effects in the packing structure and stiffness of redox-responsive ferrocene-containing polymer brushes, Eur. Polym. J.1 83 (2016) 517-528.

[15] G. Ghimire, Y. Yi, M.A. Derylo, L.A. Baker, T. Ito, Electron Propagation within Redox-Active Microdomains in Thin Films of Ferrocene-Containing Diblock Copolymers, Langmuir 31(44) (2015) 12307-12314.

[16] D.J. Eyckens, C.L. Arnold, J.D. Randall, F. Stojcevski, A. Hendlmeier, M.K. Stanfield, J. Pinson, T.R. Gengenbach, R. Alexander, L.C. Soulsby, P.S. Francis, L.C. Henderson, Fiber with Butterfly 
Wings: Creating Colored Carbon Fibers with Increased Strength, Adhesion, and Reversible Malleability, ACS Appl. Mater. Interfaces 11(44) (2019) 41617-41625.

[17] C.L. Arnold, K.M. Beggs, D.J. Eyckens, F. Stojcevski, L. Servinis, L.C. Henderson, Enhancing interfacial shear strength via surface grafting of carbon fibers using the Kolbe decarboxylation reaction, Composi. Sci. Technol. 159 (2018) 135-141.

[18] L. Servinis, K.M. Beggs, C. Scheffler, E. Wölfel, J.D. Randall, T.R. Gengenbach, B. Demir, T.R. Walsh, E.H. Doeven, P.S. Francis, L.C. Henderson, Electrochemical surface modification of carbon fibres by grafting of amine, carboxylic and lipophilic amide groups, Carbon 118 (2017) 393-403.

[19] L. Servinis, L.C. Henderson, L.M. Andrighetto, M.G. Huson, T.R. Gengenbach, B.L. Fox, A novel approach to functionalise pristine unsized carbon fibre using in situ generated diazonium species to enhance interfacial shear strength, J. Mater. Chem. A 3(7) (2015) 3360-3371.

[20] L. Servinis, K.M. Beggs, T.R. Gengenbach, E.H. Doeven, P.S. Francis, B.L. Fox, J.M. Pringle, C. Pozo-Gonzalo, T.R. Walsh, L.C. Henderson, Tailoring the fibre-to-matrix interface using click chemistry on carbon fibre surfaces, J. Mater. Chem. A 5 (2017) 11204-11213.

[21] L. Servinis, T.R. Gengenbach, M.G. Huson, L.C. Henderson, B.L. Fox, A Novel Approach to the Functionalisation of Pristine Carbon Fibre Using Azomethine 1,3-Dipolar Cycloaddition, Aust. J. Chem. (68) (2015) 335-344.

[22] A.J. Bard, C.G. Zoski, Electroanalytical chemistry : a series of advances. Volume 26 Volume 26, (2016).

[23] P. Allongue, M. Delamar, B. Desbat, O. Fagebaume, R. Hitmi, J. Pinson, J.-M. Savéant, Covalent Modification of Carbon Surfaces by Aryl Radicals Generated from the Electrochemical Reduction of Diazonium Salts, J. Am. Chem. Soc. 119(1) (1997) 201-207.

[24] M. Ceccato, A. Bousquet, M. Hinge, S.U. Pedersen, K. Daasbjerg, Using a Mediating Effect in the Electroreduction of Aryldiazonium Salts To Prepare Conducting Organic Films of High Thickness, Chem. Mater. 23(6) (2011) 1551-1557.

[25] M. Maghe, C. Creighton, L.C. Henderson, M.G. Huson, S. Nunna, S. Atkiss, N. Byrne, B.L. Fox, Using ionic liquids to reduce energy consumption for carbon fibre production, J. Mater. Chem. A 4(42) (2016) 16619-16626.

[26] M. Mooste, E. Kibena-Põldsepp, M. Marandi, L. Matisen, V. Sammelselg, K. Tammeveski, Electrochemical properties of gold and glassy carbon electrodes electrografted with an anthraquinone diazonium compound using the rotating disc electrode method, RSC Adv. 6(47) (2016) 40982-40990.

[27] M. Mooste, E. Kibena, A. Sarapuu, L. Matisen, K. Tammeveski, Oxygen reduction on thick anthraquinone films electrografted to glassy carbon, J. Electroanal. Chem. 702 (2013) 8-14.

[28] S. Chernyy, A. Bousquet, K. Torbensen, J. Iruthayaraj, M. Ceccato, S.U. Pedersen, K. Daasbjerg, Elucidation of the Mechanism of Redox Grafting of Diazotated Anthraquinone, Langmuir 28(25) (2012) 9573-9582. 
[29] B.D. Assresahegn, T. Brousse, D. Bélanger, Advances on the use of diazonium chemistry for functionalization of materials used in energy storage systems, Carbon 92 (2015) 362-381.

[30] M.W. Lehmann, D.H. Evans, Anomalous behavior in the two-step reduction of quinones in acetonitrile, J. Electroanal. Chem. 500(1) (2001) 12-20.

[31] G. Deniau, L. Azoulay, L. Bougerolles, S. Palacin, Surface Electroinitiated Emulsion Polymerization: Grafted Organic Coatings from Aqueous Solutions, Chem. Mater. 18(23) (2006) 5421-5428.

[32] C.L. Arnold, K.M. Beggs, D.J. Eyckens, F. Stojcevski, L. Servinis, L.C. Henderson, Enhancing interfacial shear strength via surface grafting of carbon fibers using the Kolbe decarboxylation reaction, Compos. Sci. Technol. 159 (2018) 135-141.

[33] F. Stojceveski, A. Hendlmeier, J. Randall, C. Arnold, M. Stanfield, D. Eyckens, R. Alexander, L. Henderson, Effect of Tow Size and Interface Interaction on Interfacial Shear Strength Determined by Iosipescu (V-Notch) Testing in Epoxy Resin, Materials 11(9) (2018) 1786.

[34] D.J. Eyckens, C.L. Arnold, J.D. Randall, F. Stojcevski, A. Hendlmeier, M.K. Stanfield, J. Pinson, T.R. Gengenbach, R. Alexander, L.C. Soulsby, P.S. Francis, L.C. Henderson, Fiber with Butterfly Wings: Creating Colored Carbon Fibers with Increased Strength, Adhesion, and Reversible Malleability, ACS Appl.Mater. Interfaces 11(44) (2019) 41617-41625.

[35] J.D. Randall, D.J. Eyckens, L. Servinis, F. Stojcevski, L.A. O'Dell, T.R. Gengenbach, B. Demir, T.R. Walsh, L.C. Henderson, Designing carbon fiber composite interfaces using a 'graft-to' approach: Surface grafting density versus interphase penetration, Carbon 146 (2019) 88-96.

[36] D.J. Eyckens, B. Demir, J.D. Randall, T.R. Gengenbach, L. Servinis, T.R. Walsh, L.C. Henderson, Using molecular entanglement as a strategy to enhance carbon fiber-epoxy composite interfaces, Compos. Sci. Technol. 196 (2020) 108225.

[37] L. Tessier, G. Deniau, B. Charleux, S. Palacin, Surface Electroinitiated Emulsion Polymerization (SEEP): A Mechanistic Approach, Chem. Mater. 21(18) (2009) 4261-4274.

[38] R.S.K.A. Gamage, A.J. McQuillan, B.M. Peake, Ultraviolet-visible and electron paramagnetic resonance spectroelectrochemical studies of the reduction products of some anthraquinone sulphonates in aqueous solutions, Journal of the Chemical Society, Farad. Trans. 87(22) (1991) 36533660.

[39] C. Batchelor-McAuley, Q. Li, S.M. Dapin, R.G. Compton, Voltammetric Characterization of DNA Intercalators across the Full pH Range: Anthraquinone-2,6-disulfonate and Anthraquinone-2sulfonate, J. Phys. Chem. B. 114(11) (2010) 4094-4100.

[40] C. Batchelor-McAuley, B.R. Kozub, D. Menshykau, R.G. Compton, Voltammetric Responses of Surface-Bound and Solution-Phase Anthraquinone Moieties in the Presence of Unbuffered Aqueous Media, J. Phys. Chem. C 115(3) (2011) 714-718. 
[41] M. Weissmann, O. Crosnier, T. Brousse, D. Bélanger, Electrochemical study of anthraquinone groups, grafted by the diazonium chemistry, in different aqueous media-relevance for the development of aqueous hybrid electrochemical capacitor, Electrochim. Acta 82 (2012) 250-256.

[42] J.D. Randall, M.K. Stanfield, D.J. Eyckens, J. Pinson, L.C. Henderson, Expanding the scope of surface grafted polymers using electroinitiated polymerization, Langmuir (2020).

[1] T.K. Das, P. Ghosh, N.C. Das, Preparation, development, outcomes, and application versatility of carbon fiber-based polymer composites: a review, Adv. Compos. Hybrid Mater. 2(2) (2019) 214-233. 10.1007/s42114-018-0072-z

[2] Y. Chen, G. Dai, Q. Gao, Starch Nanoparticles-Graphene Aerogels with High Supercapacitor Performance and Efficient Adsorption, ACS Sustainable Chem. Eng. 7(16) (2019) 14064-14073. 10.1021/acssuschemeng.9b02594

[3] B. Yu, X. Li, J. An, Z. Jiang, J. Yang, Interfacial and Glass Transition Properties of SurfaceTreated Carbon Fiber Reinforced Polymer Composites under Hygrothermal Conditions, Engineered Science 2 (2018) 67-73. 10.30919/es8d628

[4] M. Ramezankhani, B. Crawford, H. Khayyam, M. Naebe, R. Seethaler, A.S. Milani, A multiobjective Gaussian process approach for optimization and prediction of carbonization process in carbon fiber production under uncertainty, Adv. Compos. Hybrid Mater. 2(3) (2019) 444-455. 10.1007/s42114-019-00107-6

[5] Z. Wu, L. Li, N. Guo, R. Yang, D. Jiang, M. Zhang, M. Zhang, Y. Huang, Z. Guo, Effect of A Vinyl Ester-Carbon Nanotubes Sizing Agent on Interfacial Properties of Carbon Fibers Reinforced Unsaturated Polyester Composites, ES Materials \& Manufacturing 6 (2019) 38-48.

10.30919/esmm5f601

[6] H. Zhao, L. Chen, J. Yun, L. Tang, Z. Wen, X. Zhang, J. Gu, Improved Thermal Stabilities, Ablation and Mechanical Properties for Carbon Fibers/Phenolic Resins Laminated Composites Modified by Silicon-containing Polyborazine, Engineered Science 2 (2018) 57-66. 10.30919/es8d726

[7] G. Guo, V.L. Finkenstadt, Y. Nimmagadda, Mechanical properties and water absorption behavior of injection-molded wood fiber/carbon fiber high-density polyethylene hybrid composites, Adv. Compos. Hybrid Mater. 2(4) (2019) 690-700. 10.1007/s42114-019-00116-5

[8] L. Zhao, Q. Ge, J. Sun, J. Peng, X. Yin, L. Huang, J. Wang, H. Wang, L. Wang, Fabrication and characterization of polyphenylene sulfide composites with ultra-high content of carbon fiber fabrics, Adv. Compos. Hybrid Mater. 2(3) (2019) 481-491. 10.1007/s42114-019-00111-w

[9] M.N. Uddin, J.M. George, V.R. Patlolla, R. Asmatulu, Investigating the effects of UV light and moisture ingression on low-impact resistance of three different carbon fiber-reinforced composites, Adv. Compos. Hybrid Mater. 2(4) (2019) 701-710. 10.1007/s42114-019-00117-4

[10] M.N. Uddin, H.T.N. Gandy, M.M. Rahman, R. Asmatulu, Adhesiveless honeycomb sandwich structures of prepreg carbon fiber composites for primary structural applications, Adv. Compos. Hybrid Mater. 2(2) (2019) 339-350. 10.1007/s42114-019-00096-6

[11] L. Shi, G. Song, P. Li, X. Li, D. Pan, Y. Huang, L. Ma, Z. Guo, Enhancing interfacial performance of epoxy resin composites via in-situ nucleophilic addition polymerization modification of carbon fibers with hyperbranched polyimidazole, Compos. Sci. Technol. 201 (2021) 108522. https://doi.org/10.1016/j.compscitech.2020.108522

[12] Y. Zhang, L. Zhan, Preparation and Damping Properties of Al2O3 Hollow Spheres/Epoxy Composites Encapsulating Q195 Steel Pipes, ES Materials \& Manufacturing (2020). 10.30919/esmm5f925

[13] F. Stojcevski, O. Siddique, G. Meric, J.D. Randall, N.S. Emonson, L.C. Henderson, Using in situ polymerisation to enhance adhesion of dissimilar materials, Int. J. Adhes. Adhes. 104 (2021) 102740. https://doi.org/10.1016/j.ijadhadh.2020.102740

[14] R.B. Ashok, C.V. Srinivasa, B. Basavaraju, Study on morphology and mechanical behavior of areca leaf sheath reinforced epoxy composites, Adv. Compos. Hybrid Mater. 3(3) (2020) 365-374. $10.1007 / \mathrm{s} 42114-020-00169-\mathrm{x}$ 
[15] N.C. Adak, S. Chhetri, N.C. Murmu, P. Samanta, T. Kuila, Analytical and experimental investigation on magnetorheological behavior of $\mathrm{CoFe} 2 \mathrm{O} 4-\mathrm{rGO}$-incorporated epoxy fluid composites, Adv. Compos. Hybrid Mater. 2(2) (2019) 266-278. 10.1007/s42114-019-00086-8

[16] I. Bustero, I. Gaztelumendi, I. Obieta, M.A. Mendizabal, A. Zurutuza, A. Ortega, B. Alonso, Free-standing graphene films embedded in epoxy resin with enhanced thermal properties, Adv. Compos. Hybrid Mater. 3(1) (2020) 31-40. 10.1007/s42114-020-00136-6

[17] M. Sabu, E. Bementa, Y. Jaya Vinse Ruban, S. Ginil Mon, A novel analysis of the dielectric properties of hybrid epoxy composites, Adv. Compos. Hybrid Mater. 3(3) (2020) 325-335. 10.1007/s42114-020-00166-0

[18] D.J. Eyckens, B. Demir, J.D. Randall, T.R. Gengenbach, L. Servinis, T.R. Walsh, L.C. Henderson, Using molecular entanglement as a strategy to enhance carbon fiber-epoxy composite interfaces, Compos. Sci. Technol. 196 (2020) 108225. 10.1016/j.compscitech.2020.108225 